\title{
Argonne
}

NATIONAL LABORATORY

Energy Systems Division

\section{Computational Mechanics}

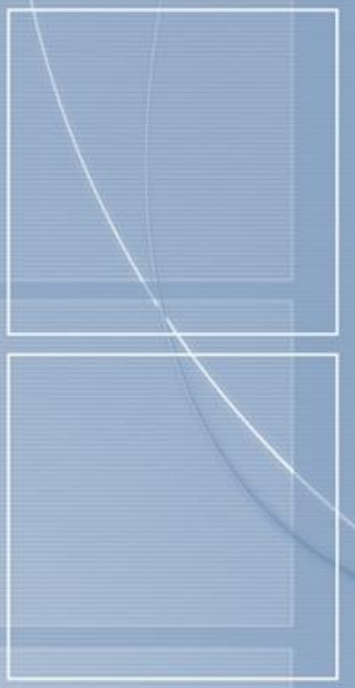

Research and Support

for Aerodynamics and Hydraulics \section{at TFHRC}

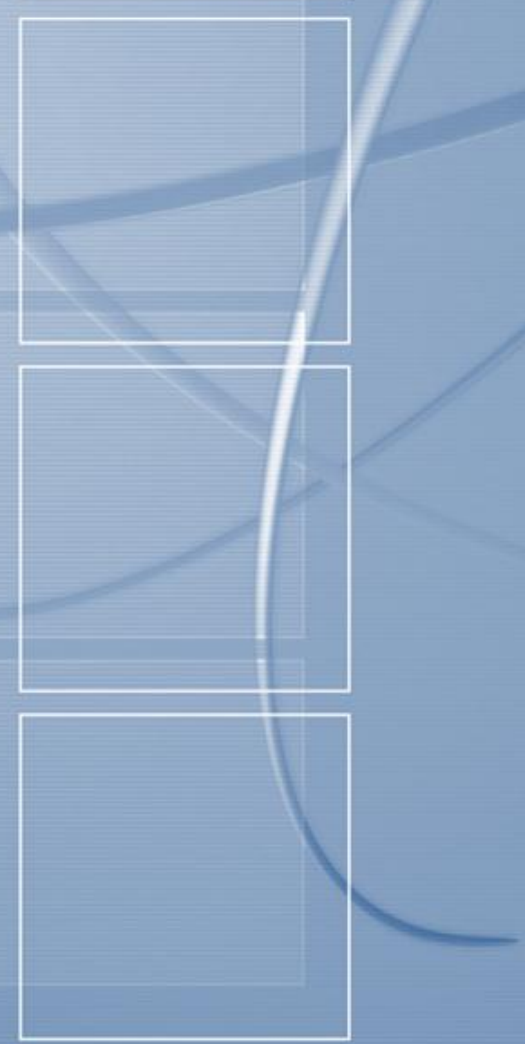

Year 2 Quarter 3 Progress Report 
About Argonne National Laboratory

Argonne is a U.S. Department of Energy laboratory managed by UChicago Argonne, LLC under contract DE-AC02-06CH11357. The Laboratory's main facility is outside Chicago, at 9700 South Cass Avenue, Argonne, Illinois 60439. For information about Argonne and its pioneering science and technology programs, see www.anl.gov.

\section{Availability of This Report}

This report is available, at no cost, at http://www.osti.gov/bridge. It is also available

on paper to the U.S. Department of Energy and its contractors, for a processing fee, from:

U.S. Department of Energy

Office of Scientific and Technical Information

P.O. Box 62

Oak Ridge, TN 37831-0062

phone (865) 576-8401

fax (865) 576-5728

reports@adonis.osti.gov 


\section{Computational Mechanics Research and Support for Aerodynamics and Hydraulics at TFHRC, Year 2 Quarter 3 Progress Report}

by

S.A. Lottes ${ }^{1}$, C. Bojanowski ${ }^{1}$, J. Shen ${ }^{2}$, Z. Xie ${ }^{2}$, and Y. Zhai ${ }^{2}$

${ }^{1}$ Transportation Research and Analysis Computing Center (TRACC)

Energy Systems Division, Argonne National Laboratory

${ }^{2}$ Turner-Fairbank Highway Research Center

submitted to

Kornel Kerenyi ${ }^{1}$ and Harold Bosch ${ }^{1}$

${ }^{1}$ Turner-Fairbank Highway Research Center

September 2012 


\section{Table of Contents}

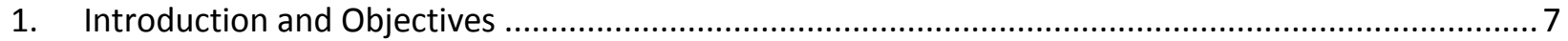

1.1. Computational Fluid Dynamics Summary................................................................................ 7

2. Computational Fluid Dynamics for Hydraulic and Aerodynamic Research ...................................... 9

2.1. Modeling of the Wind Tunnel Laboratory at TFHRC ................................................................ 9

2.2. Computational Modeling and Analysis of Flow through Large Culverts for Fish Passage ............. 14

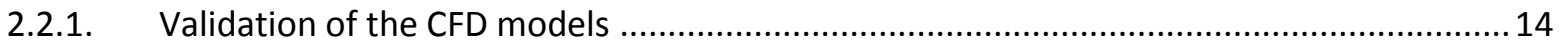

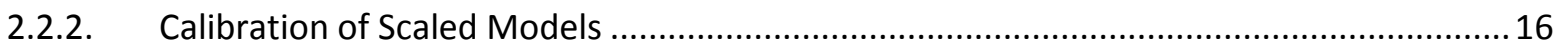

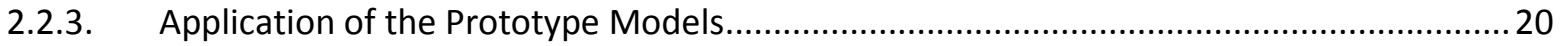

2.2.4. Design Aids Based on the Velocity Contour Results ...................................................... 21

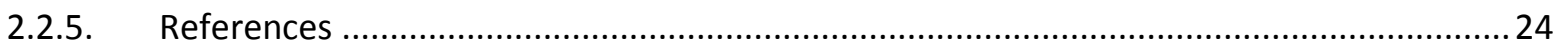

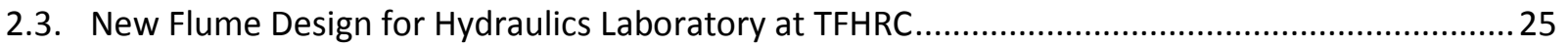

2.4. Modeling of Truck Generated Salt Spray under Bridge with Sliding Mesh .................................28

2.5. Modeling of In-situ Scour Testing Device Design Alternatives ................................................ 31

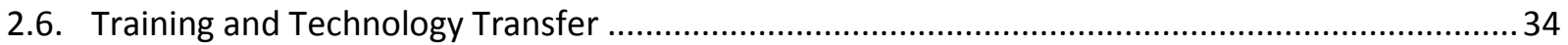

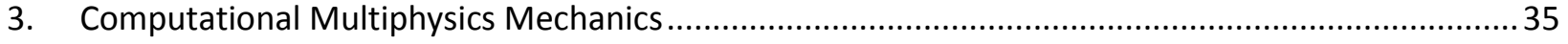

3.1. Multiphysics Coupling of STAR-CCM+ and LS-DYNA for Bridge and Cable Analysis under Wind Loading. 


\section{List of Figures}

Figure 2.1: Auxiliary model to study the mass flow rate through the rotating pulley........

Figure 2.2: Flow through the simplified model with the rotating pulley based on the moving reference frame

Figure 2.3: Mass flow rate through the pulley. 11

Figure 2.4: Velocity field in the model without the pulley 12

Figure 2.5: Close up view on the testing sections in the model 12

Figure 2.6: Comparison of the velocities at several locations in the test section for two models: with stationary disk pulley and no pulley at all.

Figure 2.7 CFD simulated vs. PIV observed mean velocities (upper) and CFD simulated vs. ADV observed mean velocities (lower)... 16

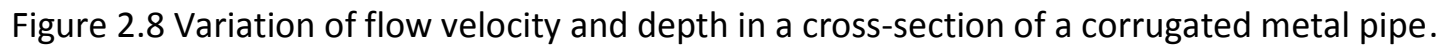
.18

Figure 2.9 Comparison of original CFD model and scaled CFD model normalized depth-averaged velocity curves at 0 in bed elevation 19

Figure 2.10 Comparison of original CFD model and scaled CFD model normalized depth-averaged velocity curves at 5.4 in bed elevation

Figure 2.11 Comparison of original CFD model and scaled CFD model normalized depth-averaged velocity curves at 10.8 in bed elevation 20

Figure 2.12 Velocity distribution (cm/s) of the prototypical culvert (trough section) for $2 \mathrm{ft}$ water depth without bed elevation

Figure 2.13 Velocity distribution $(\mathrm{cm} / \mathrm{s})$ of the prototypical culvert (trough section) for $2 \mathrm{ft}$ water depth with $0.15 \mathrm{D}$ bed elevation

Figure 2.14 Velocity distribution $(\mathrm{cm} / \mathrm{s}$ ) of the prototypical culvert (trough section) for $2 \mathrm{ft}$ water depth with $0.3 \mathrm{D}$ bed elevation.

Figure 2.15 Flow path for the selected fish design criteria of velocity and depth

Figure 2.16 Define fish path based on the combination of dimensionless water depth and flow velocity 23

Figure 2.17 A conceptual drawing of the preliminary inlet design..... 25

Figure 2.18 Velocity vectors with concentric pipe inlet with large side slot 26 
Figure 2.19 Velocity vectors with concentric pipe inlet with front and side slots.

Figure 2.20 Velocity vectors with pipe inlet and concentric porous media

Figure 2.21: Different geometry conditions under the bridge 28

Figure 2.22: Location of the wall for tunneling effect studies. 29

Figure 2.23: Cumulative plot presenting number of parcels at the bridge beam level in basic cases ....... 30

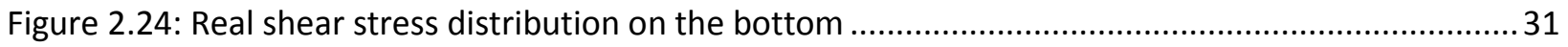

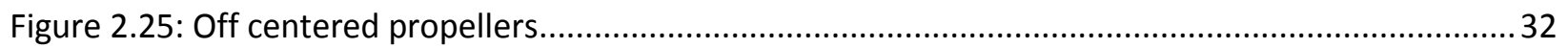

Figure 2.26: Shear stress distribution under the propeller at two different time instances....................32

Figure 2.27: Location of point probes for shear stress histories ................................................... 33

Figure 2.28: Shear stress at radial monitor points................................................................... 33

Figure 3.1 Scheme of coupling between LS-DYNA and STAR-CCM+............................................. 36

Figure 3.2 Deformation of the cable (left) and flow around it (right) after 0.4 sec..............................38

Figure 3.3 Oscillations of the cable in simulations with different damping parameters......................... 39

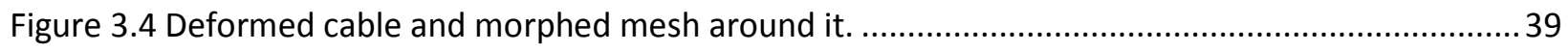




\section{List of Tables}

Table 2.1 General design requirements for fish passage in the state of Maryland.................................22

Table 2.2: Final set of analyzed cases for salt-spray generation study ................................................29 


\section{Introduction and Objectives}

The computational fluid dynamics (CFD) and computational structural mechanics (CSM) focus areas at Argonne's Transportation Research and Analysis Computing Center (TRACC) initiated a project to support and compliment the experimental programs at the Turner-Fairbank Highway Research Center (TFHRC) with high performance computing based analysis capabilities in August 2010. The project was established with a new interagency agreement between the Department of Energy and the Department of Transportation to provide collaborative research, development, and benchmarking of advanced three-dimensional computational mechanics analysis methods to the aerodynamics and hydraulics laboratories at TFHRC for a period of five years, beginning in October 2010. The analysis methods employ well benchmarked and supported commercial computational mechanics software. Computational mechanics encompasses the areas of Computational Fluid Dynamics (CFD), Computational Wind Engineering (CWE), Computational Structural Mechanics (CSM), and Computational Multiphysics Mechanics (CMM) applied in Fluid-Structure Interaction (FSI) problems.

The major areas of focus of the project are wind and water effects on bridges - superstructure, deck, cables, and substructure (including soil), primarily during storms and flood events - and the risks that these loads pose to structural failure. For flood events at bridges, another major focus of the work is assessment of the risk to bridges caused by scour of stream and riverbed material away from the foundations of a bridge. Other areas of current research include modeling of flow through culverts to improve design allowing for fish passage, modeling of the salt spray transport into bridge girders to address suitability of using weathering steel in bridges, CFD analysis of the operation of the wind tunnel in the TFHRC wind engineering laboratory.

This quarterly report documents technical progress on the project tasks for the period of April through June 2012.

\subsection{Computational Fluid Dynamics Summary}

The primary Computational Fluid Dynamics (CFD) activities during the quarter concentrated on the development of models and methods needed to continue the ongoing work in scour modeling, culvert modeling, CFD analysis of the Turner-Fairbank wind tunnel, CFD modeling and analysis of salt spray from 
large trucks passing under bridges using weathering steel, and modeling and analysis of concept testing for an in-situ scour device to measure scour related properties of sediment bed material. During this quarter the effects of spokes in the large pulley wheel in front of one of the fan intakes of the wind tunnel were analyzed, most of the current culvert work was completed and is summarized in Section 2.2, design analysis of the new TFHRC live bed scour flume inlet section considered inlet pipe geometry alternatives with respect to achieving uniform transverse flow in the downstream test section, mud flaps were added to the truck model used in weathering steel salt spray analysis, and a concept for an in situ scour sediment property measurement device using a propeller to generate bed shear stress was investigated with CFD. 


\section{Computational Fluid Dynamics for Hydraulic and Aerodynamic Research}

\subsection{Modeling of the Wind Tunnel Laboratory at TFHRC}

The geometry files provided for the initial development of the wind tunnel and room model indicated the pulley on the fan drive shaft was a solid disk. A visit to TFHRC in January, 2012, included a tour of the wind tunnel laboratory, and during that visit, it was noted that the pulley was not a solid disk but was open with six spokes. The model was modified to have a pulley that matches the 6 spoke wheel of the laboratory, and the model was moved from version 6.04 to 7.02 of STAR-CCM+. The open, spoked pulley on the side of the wind tunnel with the least resistance for return air flow was expected to increase the asymmetry in the test section in the simulations by a small amount.

An auxiliary model with reduced geometry to just the tunnel itself was built to study the effect of different models of the pulley on the mass flow rate through the tunnel. Specifically, it aimed at giving the answer to the question: how much air is let through the rotating pulley with the spokes. If the pulley is treated as a solid disk then this amount is equal to zero. On the other hand if it is not blocking the flow much while rotating, it might be treated as stationary to simplify the calculations. The geometry of the updated spokes and the simplified model are shown in Figure 2.1. The mass flow rate at the inlets was specified based on the previously completed simulations - the intake by the fan on both sides was measured. Several runs were performed to see the difference in mass flow through the pulley when using different rotation models:

- Stationary - the pulley with spokes is not rotating,

- Steady - the pulley with spokes is enclosed by a separate cylindrical region which is assigned a motion based on a moving reference frame. This motion model is preferable due to savings in the computation time when compared to the last case:

- Unsteady - the pulley motion is applied directly and the calculation is preformed using the implicit unsteady solver with a small timestep.

In each of the simulations the mass flow rate through the pulley (in the cross-section just behind the pulley) was tracked and compared. Figure 2.2 shows the flow through the simplified model with the rotating pulley model based on a moving reference frame. 

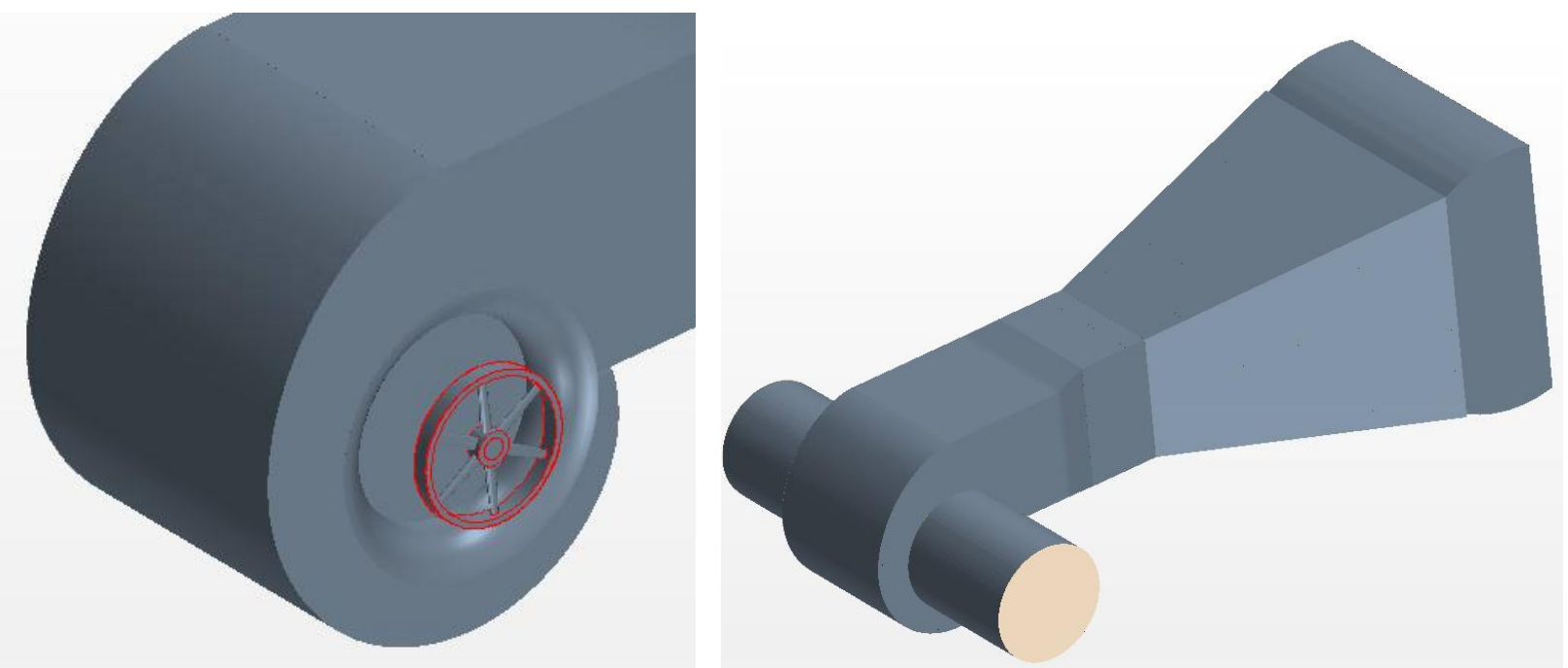

Figure 2.1: Auxiliary model to study the mass flow rate through the rotating pulley

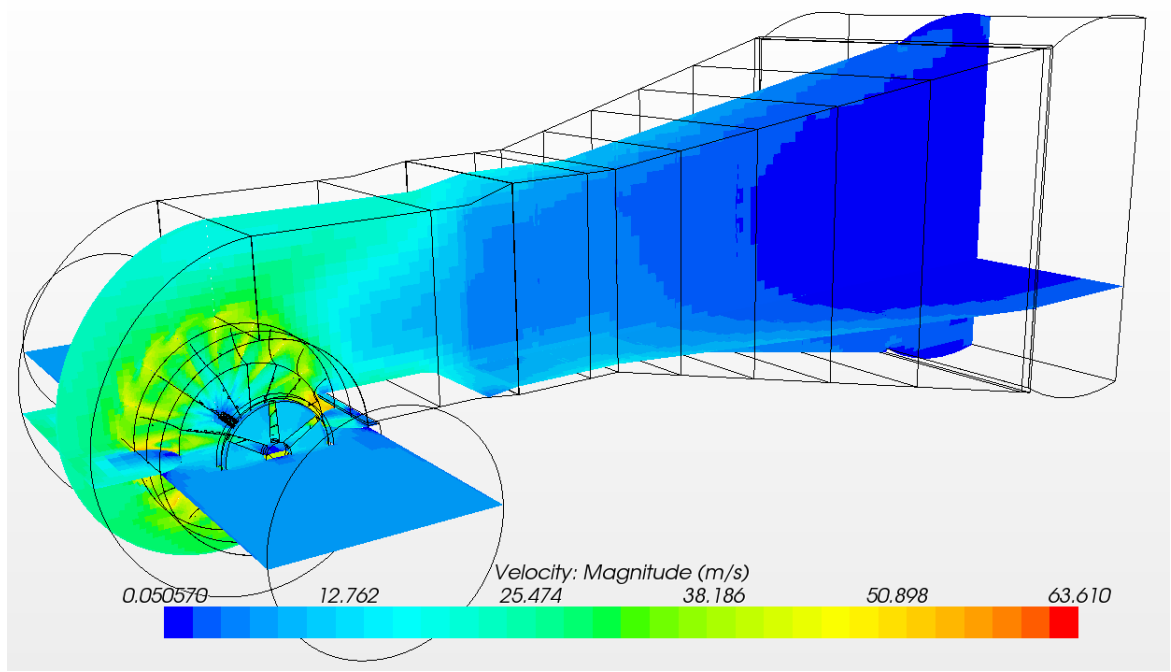

Figure 2.2: Flow through the simplified model with the rotating pulley based on the moving reference frame

Based on the test cases, it appears that modeling the pulley with direct rotation may not be feasible for modeling the whole laboratory room containing the wind tunnel. Decreasing the time step of the calculations helps to prevent divergence of the residuals in the model, but keeping the small time step small for the overall simulation time of the flow in the entire room would make the computation time unreasonably long. Calculation with this model may be investigated further if needed to better quantify the effects of spokes in the pulley wheel. The unsteady (real rotation) was simulated until 1 second of real time - two full rotations of the pulley. Work will be performed to run it for several more rotations.

Figure 2.3 shows the mass flow rate behind the pulley with spokes in two other models. They are very close in both cases. 


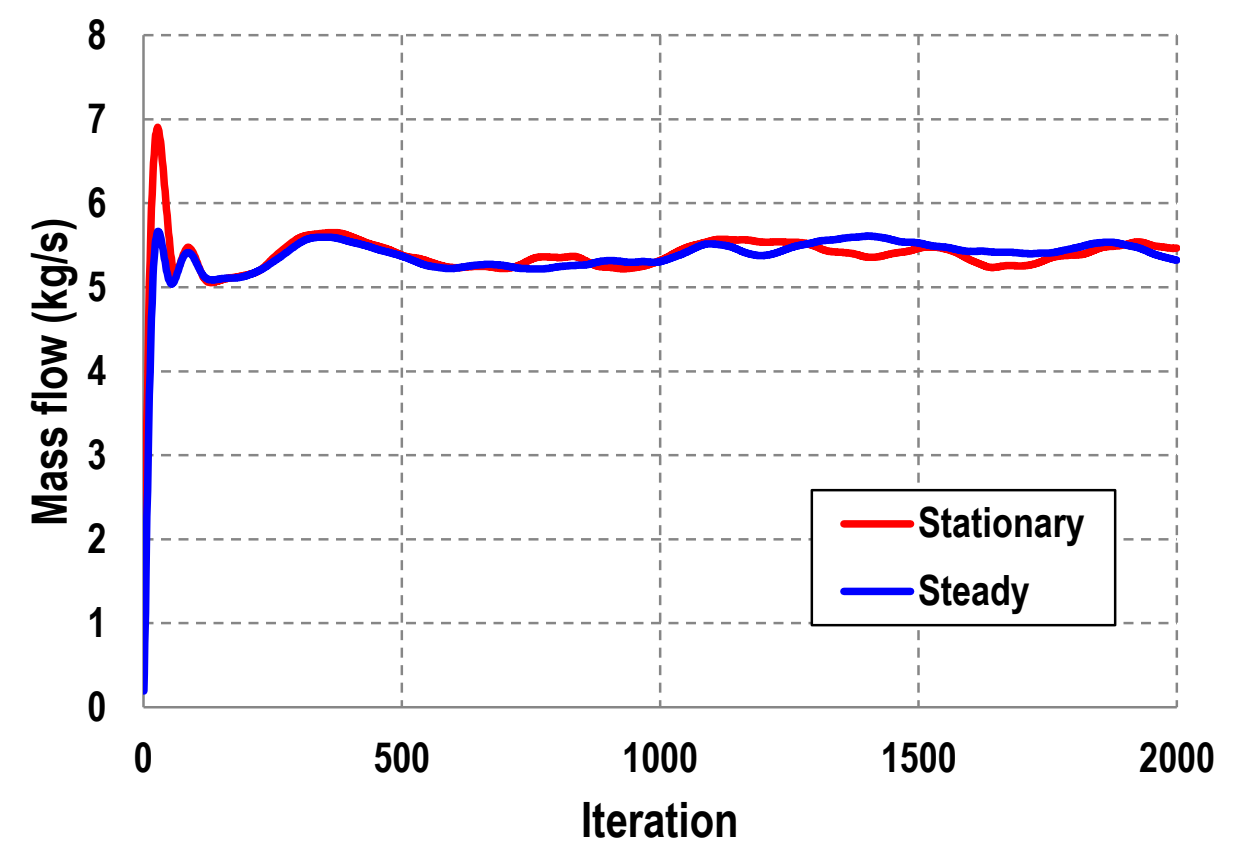

Figure 2.3: Mass flow rate through the pulley

The conclusions from these studies were as follows:

- It is hard to compute the detailed effects on the flow of the pulley with spokes.

- The simplified model of rotating turbo-machinery may not work well in this case because the pulley blades have no pitch and the pulley does not appear to act as a fan.

- To bound the possible solutions two extreme cases were analyzed:

- Room with solid pulley - maximum blockage on the right hand side of the fan

- Room without the pulley - no air flow blockage.

- The solution of the rotating pulley with spokes must lay between these two cases.

- If the difference between these two cases is not significant, either solution can be used as a valid one for the case of the rotating pulley with the spokes.

Figure 2.4 shows the velocity field in the room for the model without the spokes. There was no major difference noticed when comparing to the model with the pulley. Figure 2.5 shows a close up view of the testing sections located 2, 3, 4 and $5 \mathrm{ft}$ behind the outlet of the tunnel with marked line probes. Figure 2.6 shows comparison of the velocities registered at these line probes. It can be noted that with this resolution of the plot the difference between the curves corresponding to the same location in the two models is barely noticeable. In close up view of the plot the asymmetry can be noticed on the velocity distribution for the model without the pulley indicating the room effect. The difference however on both sides is below $1 \%$. 


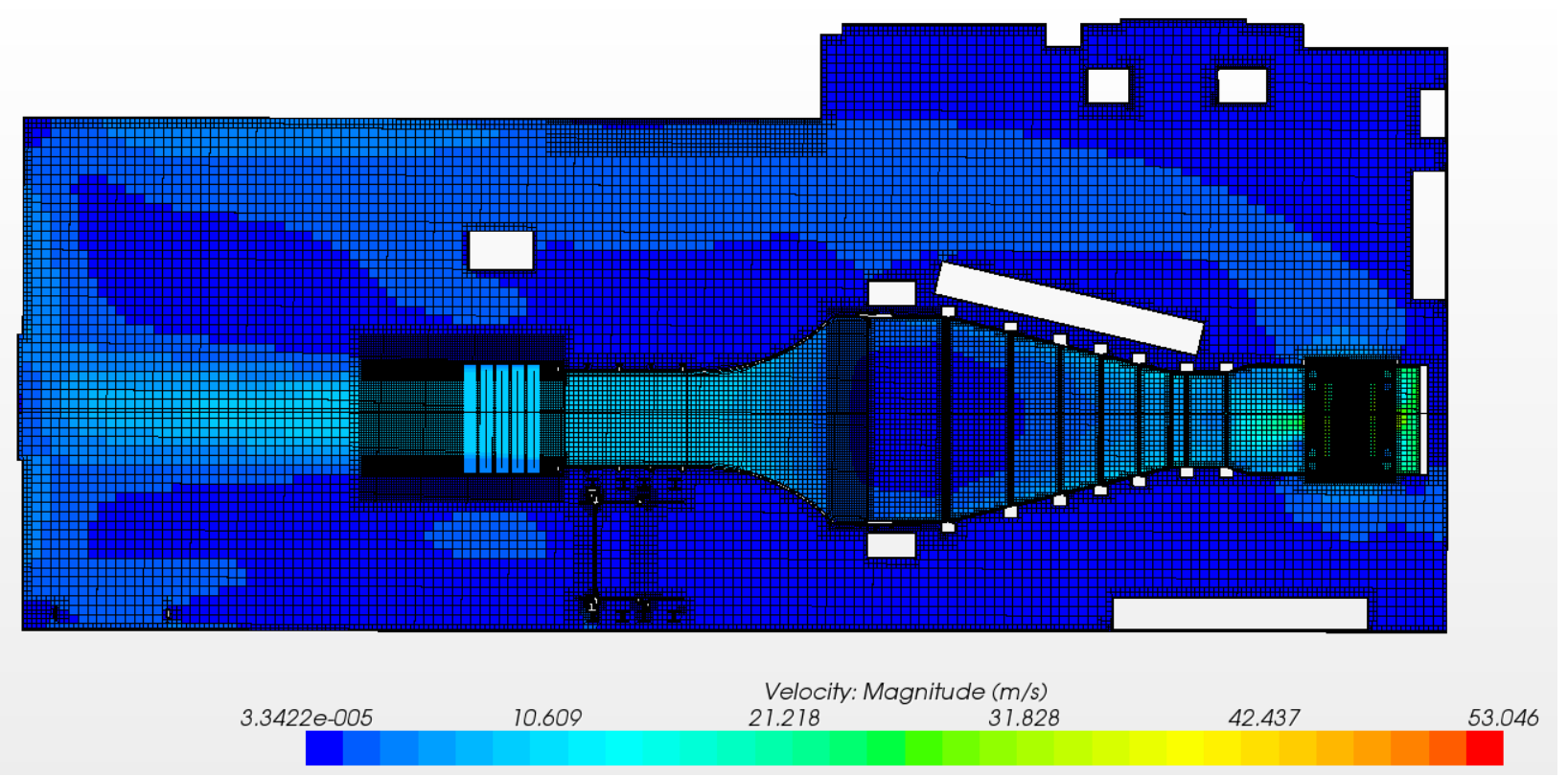

Figure 2.4: Velocity field in the model without the pulley

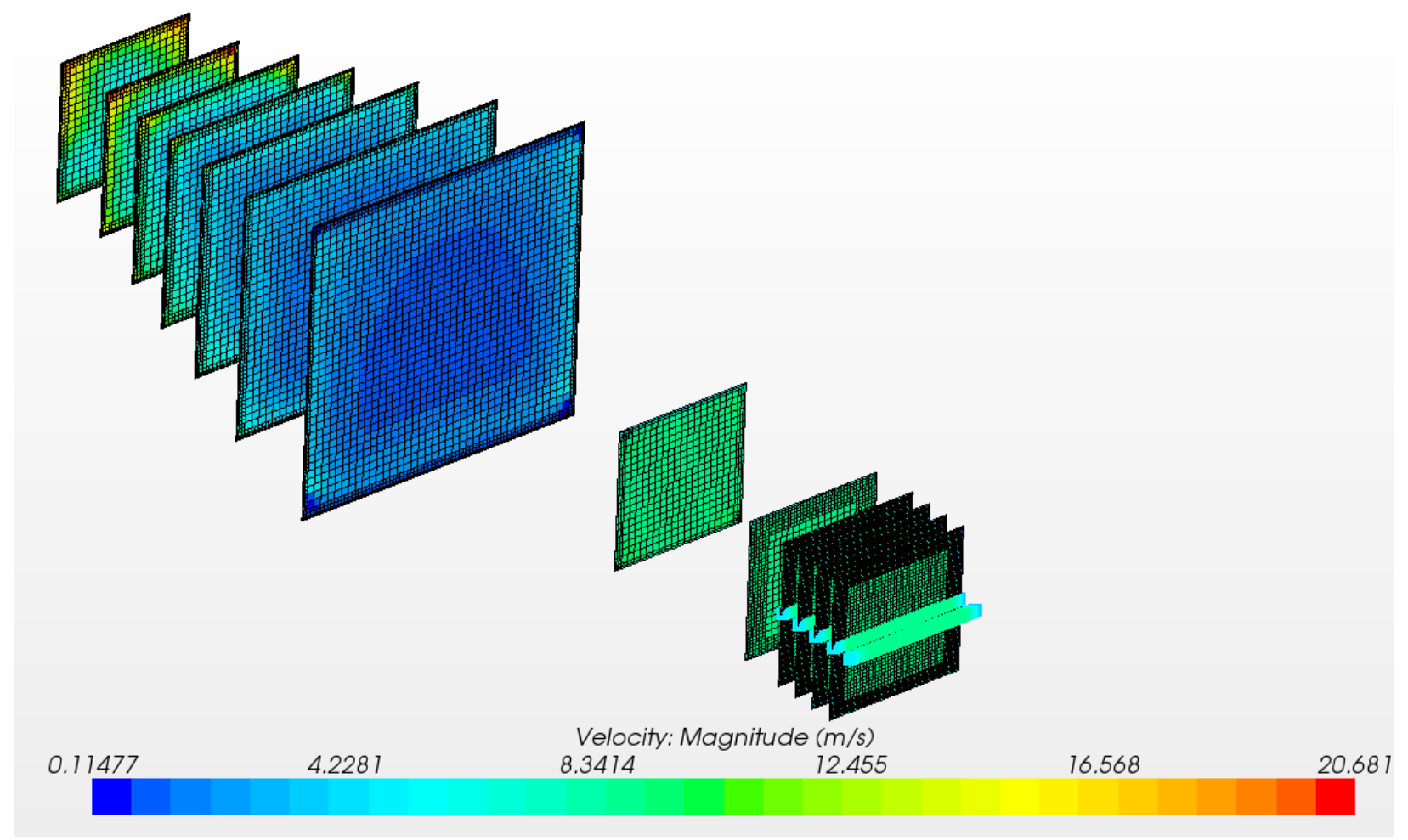

Figure 2.5: Close up view on the testing sections in the model 


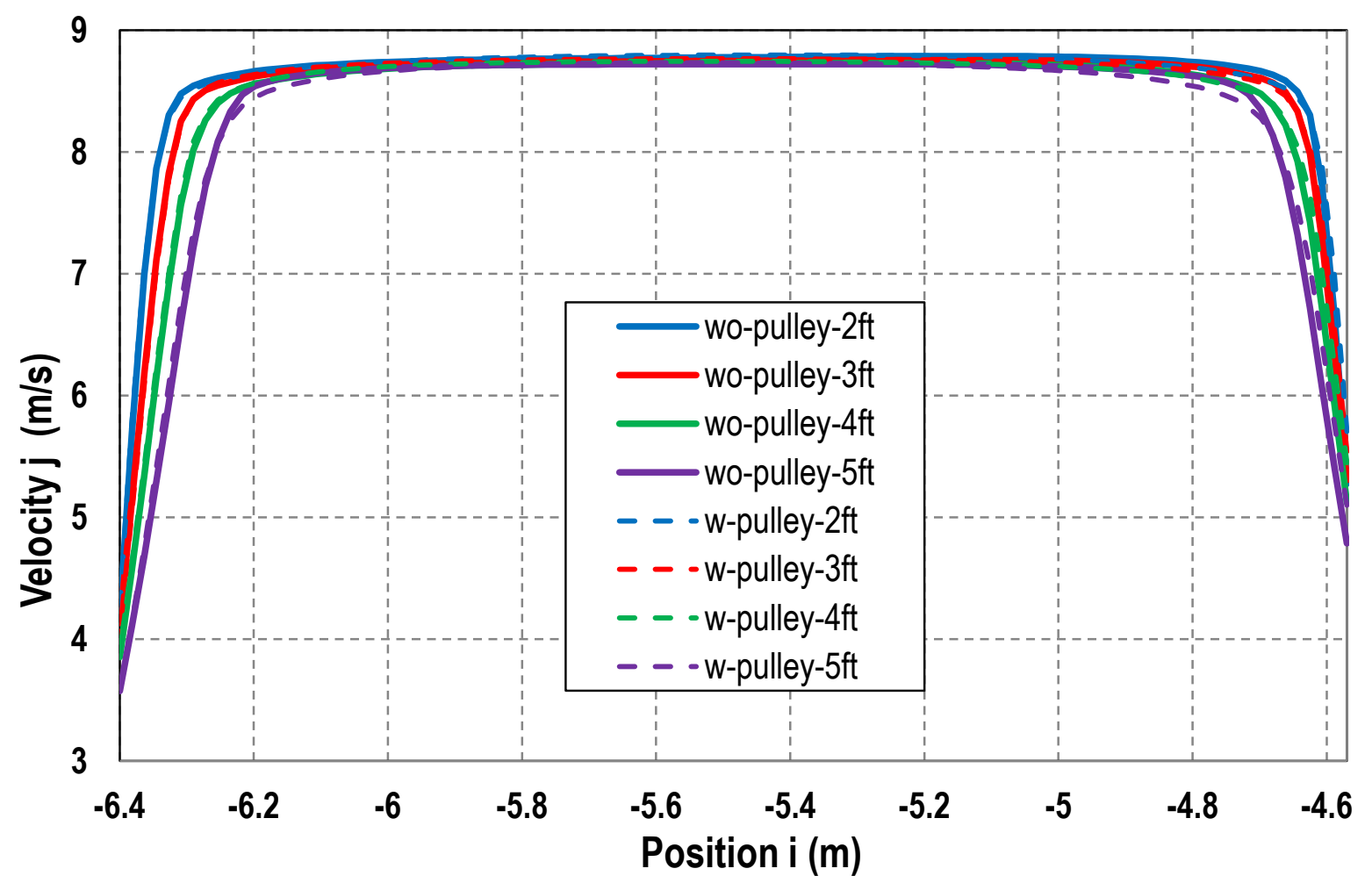

Figure 2.6: Comparison of the velocities at several locations in the test section for two models: with stationary disk pulley and no pulley at all. 


\subsection{Computational Modeling and Analysis of Flow through Large Culverts for Fish Passage}

Fish passage through culverts is an important component of road and stream crossing design. As water runoff volume increases, the flow often actively degrades waterways at culverts and may interrupt natural fish migration. Culverts are fixed structures that do not change with changing streams and may instead become barriers to fish movement. The most common physical characteristics that create barriers to fish passage include excessive water velocity, insufficient water depth, large outlet drop heights, turbulence within the culvert, and accumulation of sediment and debris. Major hydraulic criteria influencing fish passage are: flow rates during fish migration periods, fish species, roughness, and the length and slope of the culvert.

The objective of this work is to develop approaches to CFD modeling of culvert flows and to use the models to perform analysis to assess flow regions for fish passage under a variety of flow conditions. The flow conditions to be tested with CFD analysis are defined in the tables of a work plan from TFHRC [6]. The CFD models are being verified by comparing computational results with data from experiments conducted at TFHRC. A primary goal of CFD analysis of culverts for fish passage is to determine the local cross section velocities and flow distributions in corrugated culverts under varying flow conditions. In order to evaluate the ability of fish to traverse corrugated culverts, the local average velocity in vertical strips from the region adjacent to the culvert wall out to the centerline under low flow conditions will be determined.

A primary goal of the CFD analysis during this quarter has been the detailed comparison among the results from CFD and those from Particle Image Velocimetry (PIV) and Acoustic Doppler Velocimetry (ADV). The challenge of this task included the variation of measurable area over the entire cross section by the three methods, the difference in original data grid format, and finding a simple representation of the discrepancies in velocity distribution. Most of the comparisons were done between CFD and PIV data. While ADV measurements were limited due to the significant cropping of the flow section, the ADV was considered a very reliable tool and therefore was used to cross-check the comparison done between CFD and PIV under deep water conditions. Good agreement was observed among these three methods.

\subsubsection{Validation of the CFD models}

Particle Image Velocimetry (PIV) and Acoustic Doppler Velocimetry (ADV) were two methods used to obtain the velocity data from the physical modeling. The data from physical modeling provided a reliable means to calibrate and validate the CFD modeling. For each flow condition specified in the test matrix for physical modeling [6], comparisons were made between velocity data from CFD modeling and those from physical modeling. The results of the comparison verified adequacy of the CFD modeling and helped in fine-tuning the models to better simulate the corrugated metal pipe culvert in low flow conditions. A large number of CFD model cases beyond the range of the physical modeling is in progress to extend the range of the findings to a greater variety of culvert geometry, including culvert diameters that are too large to test in the laboratory, and flow conditions. 
The model needs to be validated in order to address all critical issues that potentially affect the accuracy of CFD results. This is an important step that makes the CFD results adhere to the physical phenomena. A series of physical modeling and CFD modeling tests are conducted for validation under various flow conditions. A total test set with combinations of three water depths, two flow velocities, and three bed elevations produce an eighteen-case test matrix. For each case, the PIV measurements can be compared with CFD simulated results. The data sets can be presented as $\left(u_{i}, v_{i}\right)$, where $i=1,2,3, \ldots, 18 . u_{i}$ is the average velocity of PIV measurements; $v_{i}$ is the averaged velocity from CFD simulation. A linear regression yields a best-fit equation as shown in Equation 2.1 and Figure 2.7:

$$
v=0.25388+0.95127 u
$$

The intercept is close to zero and the coefficient is close to one. The coefficient of determination, $R^{2}$, describes how well the CFD modeling fits the PIV observations. Limited by the relatively small measurable area in the culvert cross section (especially in shallow conditions), the ADV measurements do not compare very well with the average velocity from CFD results. 

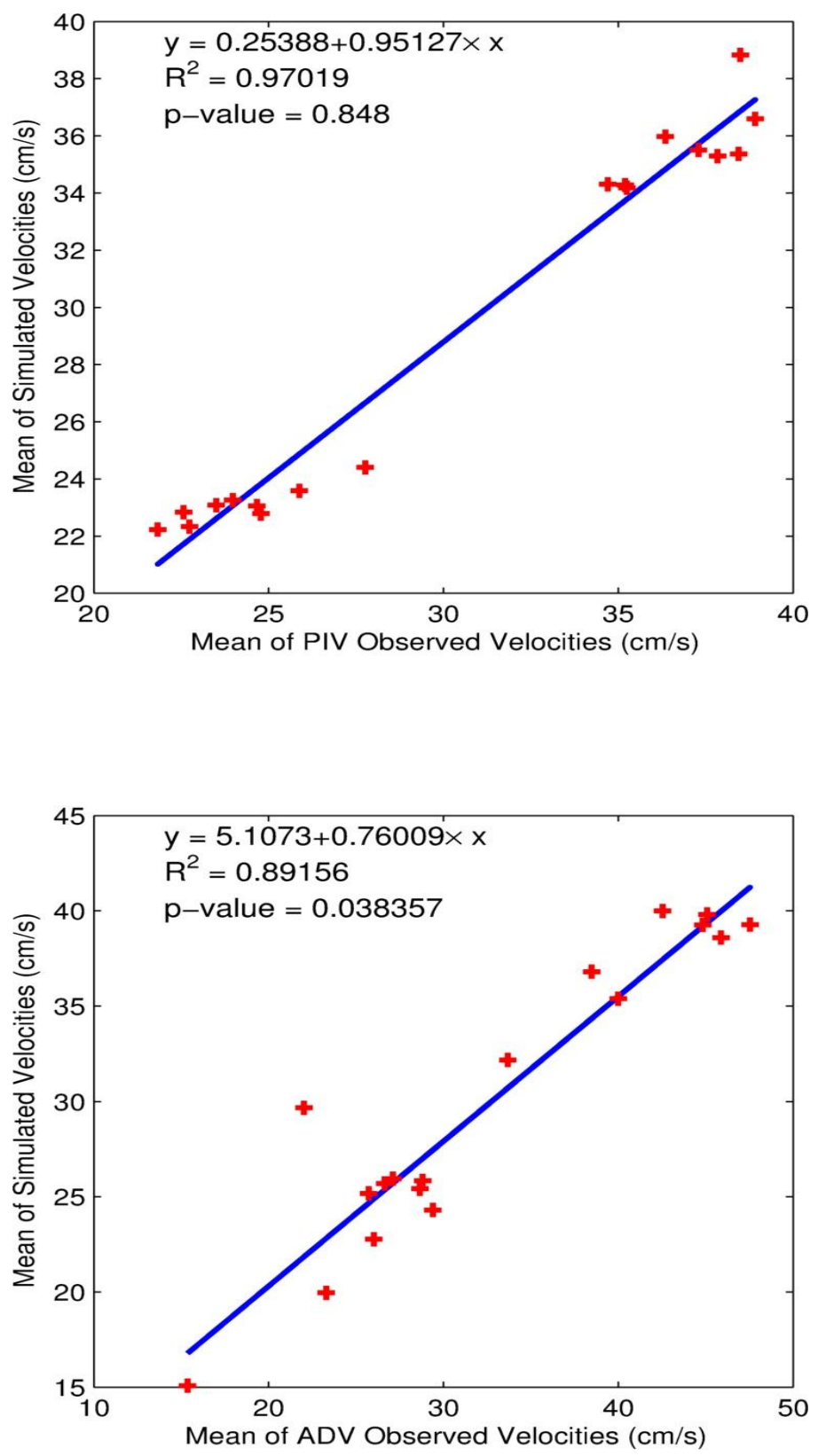

Figure 2.7 CFD simulated vs. PIV observed mean velocities (upper) and CFD simulated vs. ADV observed mean velocities (lower)

\subsubsection{Calibration of Scaled Models}

Full-scale physical modeling is often very costly, if not impossible. Therefore, conducting scaled model experiments in the laboratory to reveal the principle properties of the flow field and resolve the hydraulic problems is a very important tool. A model is a representation of a system that may be used to predict the behavior of a real-world system in some desired respect. The physical system for which the prediction is to be made is called the prototype (Young, D.F. et al., 2007). Usually a model used in bridge 
hydraulics study is much smaller than the prototype. The similitude theory is used to predict the prototype's performance from model observations. The similitude theory used in hydraulics study is based on the hypothesis that functional relationships exist among the non-dimensional parameters describing a physical system. The functions themselves must be determined empirically (Randall, 2012). Geometric similarity, kinematic similarity, and dynamic similarity are considered in the design of physical models.

One of the important parameters is the Froude number. It is a dimensionless number defined as the ratio of a characteristic velocity to gravitational wave velocity. In open channel flow, the Froude number is sometimes used in relationship with the resistance of a partially submerged object moving through water, and permits the comparison of objects of different scale. The Froude number is defined as:

$$
F_{r}=\frac{V}{\sqrt{g L}}
$$

where $\mathrm{v}$ is a characteristic velocity, $\mathrm{g}$ is the acceleration of gravity, and $\mathrm{L}$ is a length. The Froude number is named in honor of William Froude (1810-1879), a British civil engineer, mathematician and naval architect. For the problems involving free-surface flows, both gravitational and inertial forces (represented by velocity) are important and the Froude number becomes an important similarity parameter. Therefore, Froude number similitude is usually required for models involving open channel flow.

The experimental data from the physical modeling are used to validate the CFD models' accuracy and sensitivity to scale. The sensitivity to parameters such as shape, size and corrugation dimensions is tested in this section. Since the flow is open channel flow with relatively large values of roughness, it is in a fully turbulent condition. Froude number similitude criterion is used to correlate flume tests (scale model) and field conditions (prototype). That is, the hydraulic condition in the field is considered to be similar to that of the model tests if both flows have the same Froude number. For example, if a 24 inch diameter culvert is used for modeling a 96 inch structural plate pipe culvert, the linear scale ratio of prototype to model is 4 . The velocity scale ratio then becomes the square root of 4, i.e. 2 . Using this approach, the velocity of $3 \mathrm{ft} / \mathrm{s}$ measured in the laboratory flume corresponds to a flow velocity of $6 \mathrm{ft} / \mathrm{s}$ for the 96 in structural plate pipe culvert.

A length scale of $1: 2$ is used to study the scale effect. The 36 in diameter laboratory scale model culvert and a larger 72 in diameter pipe are both produced with Pro-Engineer for CFD simulation. The laboratory model culvert corrugation is 1 inch high, with spacing of 3 inches. Correspondingly the larger size corrugation (72-inch pipe) is 2 inches high, with spacing of 6 inches. The bed elevations, test water depths and river bed gravel size are all in a scale of 1:2. The flow velocities in the lab model testing are $0.71 \mathrm{fps}$ and $1.1 \mathrm{fps}$ which corresponds with $1 \mathrm{fps}$ and $1.556 \mathrm{fps}$ for the 72 -inch pipe.

In the large-scale CFD modeling, the material physics, the boundary conditions and the meshing methods are kept the same as those used with the lab scale model. If the base size of the meshing cells remains the same as that used in the lab-scale (36-inch) model, the required computation effort 
increases significantly for the large scale (72-inch) model. A parametric study is conducted to identify the optimum base size of the mesh and the refinement needed in the corrugated section (Venkata, 2011).

The depth-averaged velocity is an important characteristic velocity in this project. The local depthaveraged velocity $V$ and the local depth $y$ of the flow at any point in the culvert cross-section can be determined by the procedure illustrated in Figure 2.8. In the numerical modeling, the culvert crosssection is divided into evenly spaced strips, and then the discharge and area in each strip are determined by integrating over the strip. The ratio between the integrated discharge and area is the depth-averaged velocity.

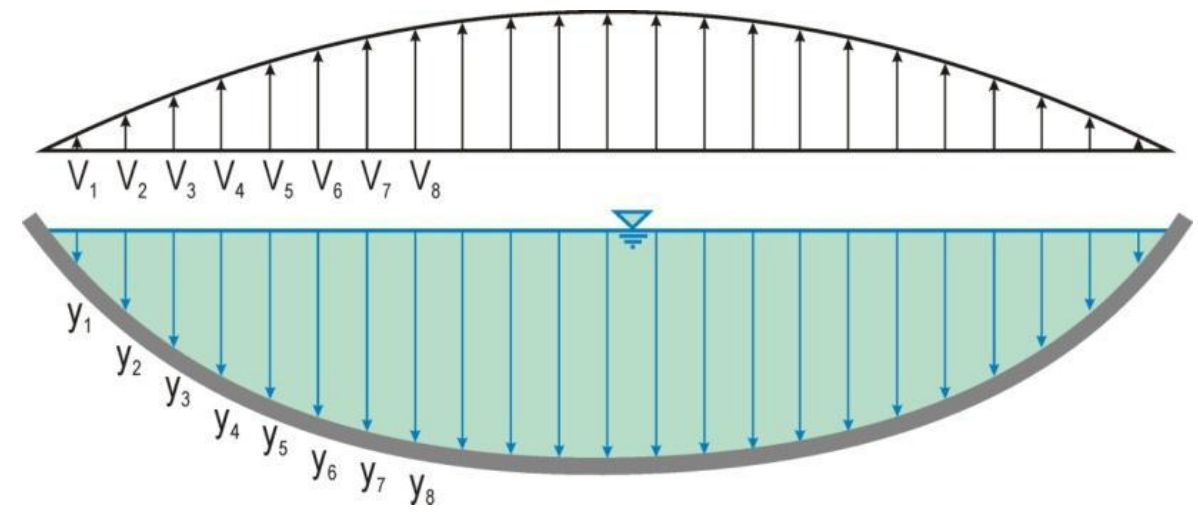

Figure 2.8 Variation of flow velocity and depth in a cross-section of a corrugated metal pipe

The proposed fish passage design is based on the local depth-averaged velocity curve. One end of the path is defined by the culvert wall. The other end of the path, towards the center of the culvert, is defined by the point where the local depth-averaged flow velocity $V$ is equal to the maximum fish swimming velocity. The depth-averaged velocity has been normalized by the cross-sectional average velocity. The position of the velocity is defined as the distance to the center of the culvert and normalized by the culvert diameter. Using the normalized position and velocity as the $\mathrm{x}$ axis and $\mathrm{y}$ axis, respectively, the scaled culvert model and the original laboratory culvert model velocity curves can be plotted in the same figure. Figure 2.9 to Figure 2.11 illustrate the comparison of the normalized local depth-averaged velocity curve of the original model and that of the scale model. The bed elevation varies from 0 in to $10.8 \mathrm{in.}$ 


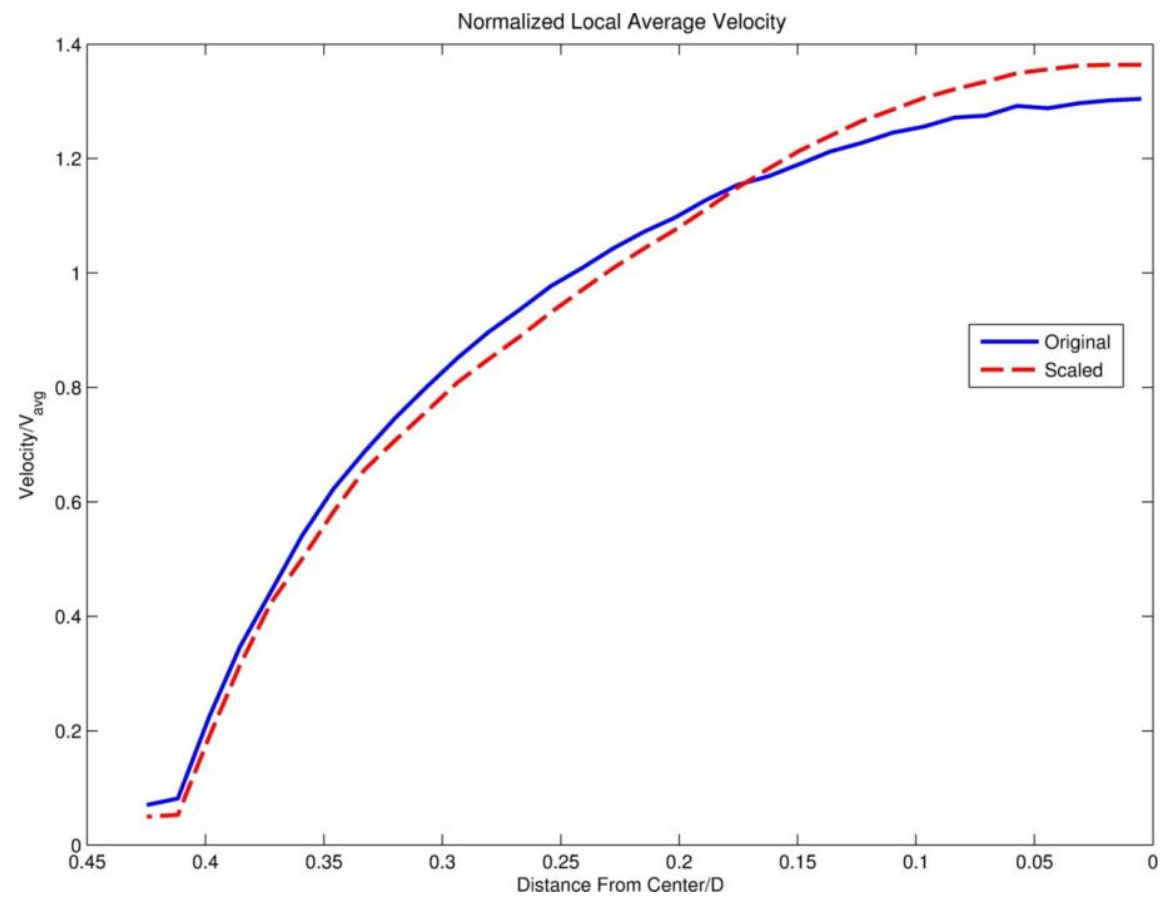

Figure 2.9 Comparison of original CFD model and scaled CFD model normalized depth-averaged velocity curves at 0 in bed elevation

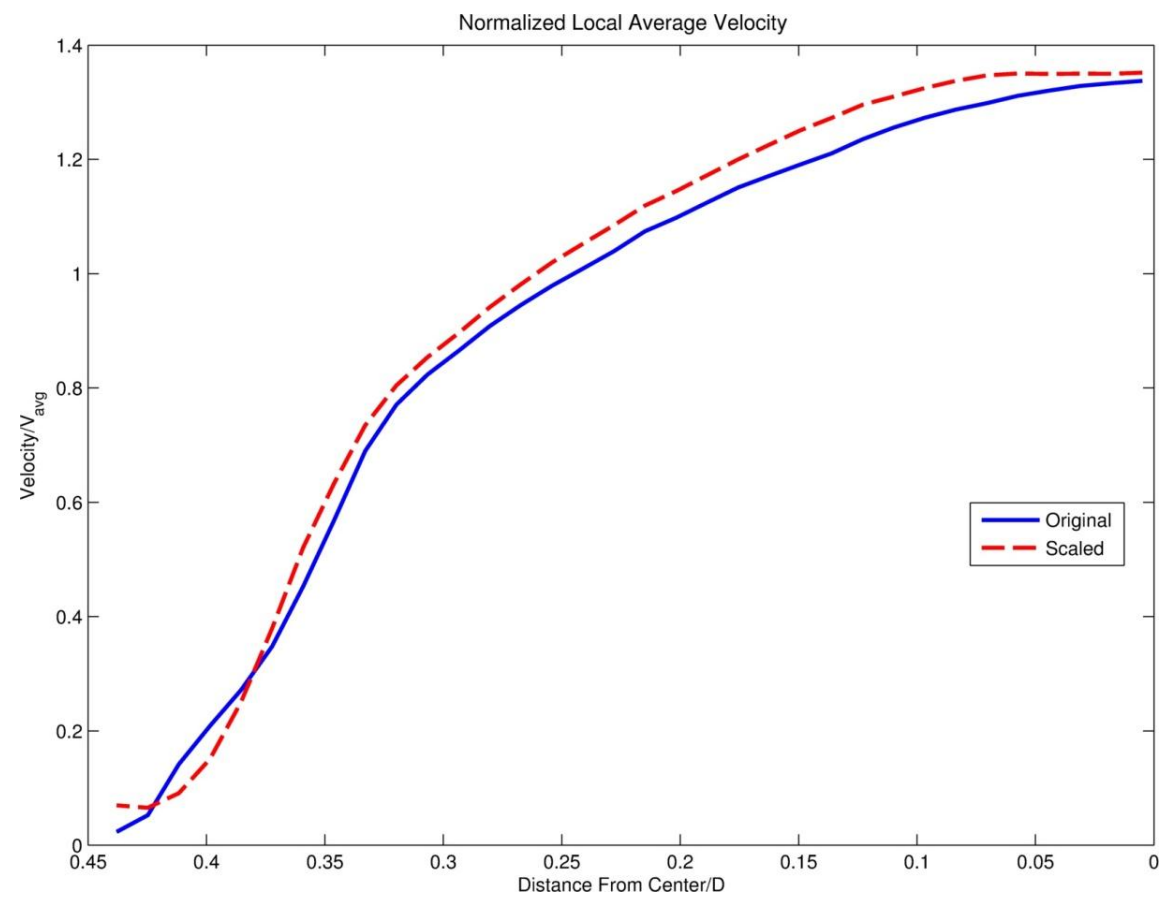

Figure 2.10 Comparison of original CFD model and scaled CFD model normalized depth-averaged velocity curves at 5.4 in bed elevation 


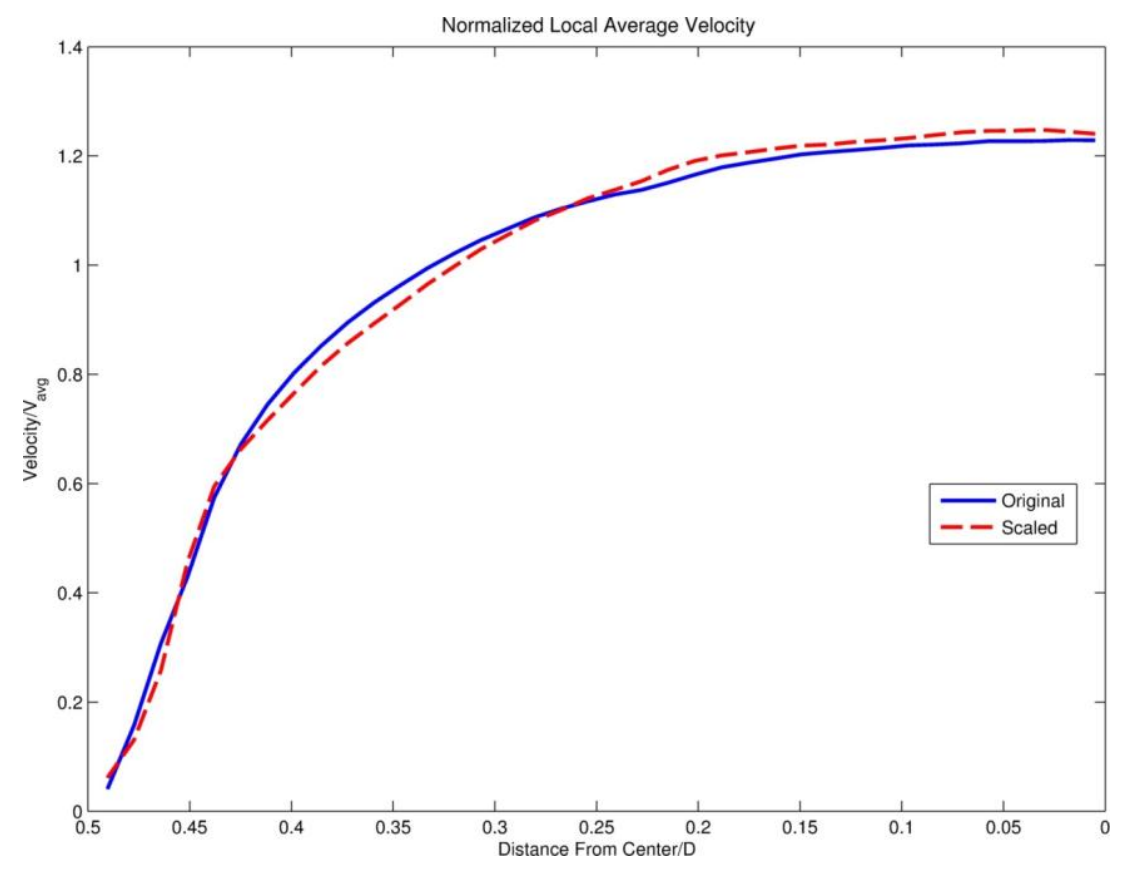

Figure 2.11 Comparison of original CFD model and scaled CFD model normalized depth-averaged velocity curves at 10.8 in bed elevation

\subsubsection{Application of the Prototype Models}

Once the truncated single phase CFD culvert model is validated and calibrated, it is applied to the prototypical size. The prototype culvert diameter is $8 \mathrm{ft}$, and has the annular corrugations of 2 inches high and 6 inch spacing. The flow depths are still 0.08D, 0.16D and 0.25D, which correspond to $0.64 \mathrm{ft}$, $1.28 \mathrm{ft}$, and $2 \mathrm{ft}$, respectively, for the 8 - $\mathrm{ft}$ pipe. The velocities are chosen as the fish passage critical velocity $1 \mathrm{fps}$ and $3 \mathrm{fps}$, and all the flow conditions were tested in the corrugated pipe and pipes with $24 \mathrm{~mm} D_{50}$ gravel. The prototype velocity distribution contours are displayed through Figure 2.12 to Figure 2.14. All of the iso-velocity contour plots demonstrate that there are steep velocity gradients close to the bed and walls, which is characteristic of turbulent flow with fully developed boundary layers.

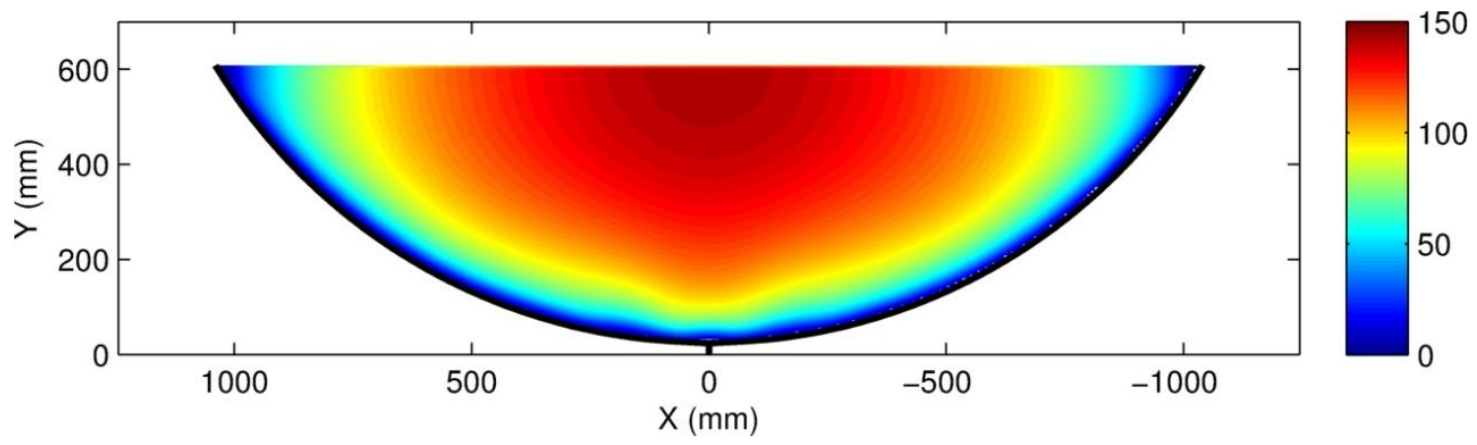

Figure 2.12 Velocity distribution $(\mathrm{cm} / \mathrm{s})$ of the prototypical culvert (trough section) for $2 \mathrm{ft}$ water depth without bed elevation 


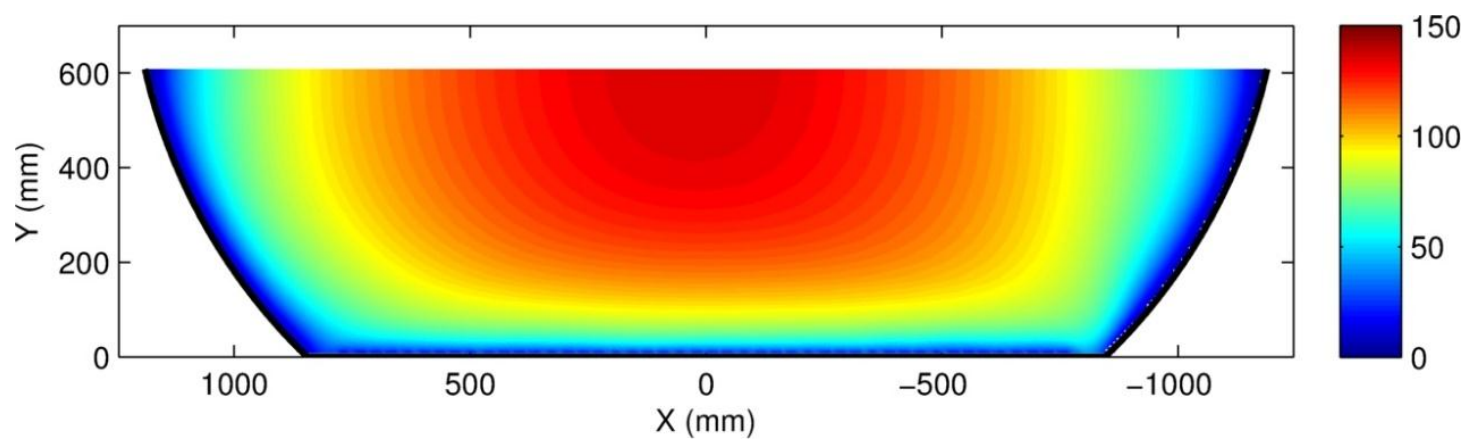

Figure 2.13 Velocity distribution ( $\mathrm{cm} / \mathrm{s}$ ) of the prototypical culvert (trough section) for $2 \mathrm{ft}$ water depth with 0.15D bed elevation

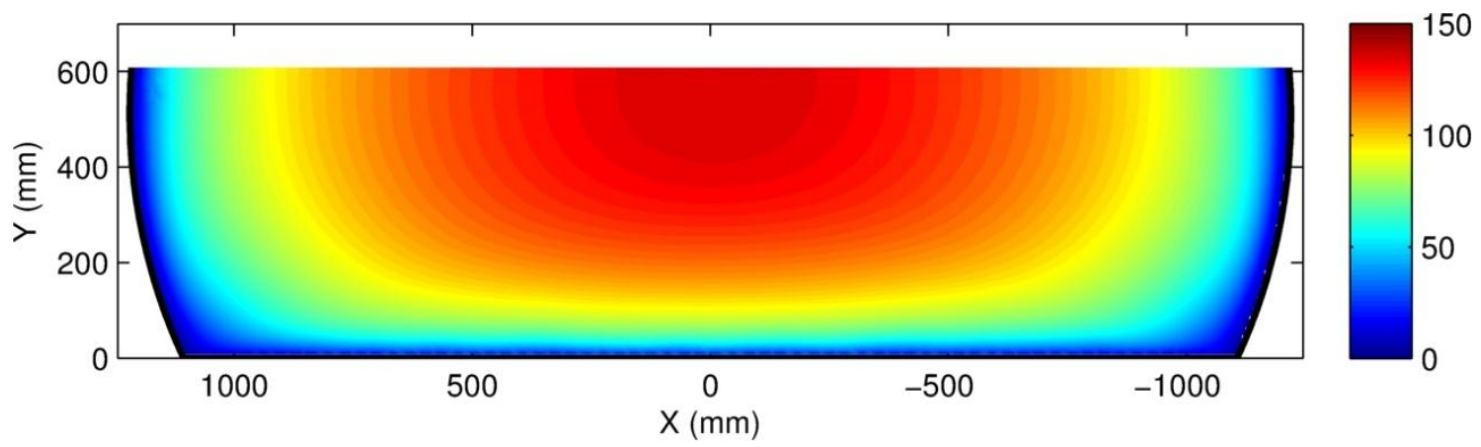

Figure 2.14 Velocity distribution $(\mathrm{cm} / \mathrm{s})$ of the prototypical culvert (trough section) for $2 \mathrm{ft}$ water depth with $0.3 \mathrm{D}$ bed elevation

\subsubsection{Design Aids Based on the Velocity Contour Results}

The validated truncated periodic boundary single phase CFD model provides the velocity distribution contour under a variety of flow conditions reliably and cost-efficiently. And the velocity of each numerical calculation grid represents the local velocity when the CFD model mesh is fine enough. The available velocity data read from the STAR-CCM+ tabulated data is adequate to do the velocity analysis and extrapolation.

In this study, a trimmed cell mesh was used to generate an extremely high quality hexahedral-based mesh for the culvert geometry. This kind of mesh model gives a structured mesh across the culvert section that is well suited for computing strip averages because the grid can be built to align cell faces with strip boundaries. When these boundaries are not aligned with cell faces, velocity data in uniform vertical strips in the cross-section are generated by interpolating the original grid velocity data from STAR-CCM+. The exported data are then used to obtain the depth averaged velocity distribution over the strips by averaging the velocities falling in each strip (using MATLAB). Table 2.1 shows the current recommendations of the design standards for fish passage in Maryland. 
Table 2.1 General design requirements for fish passage in the state of Maryland

\begin{tabular}{|l|l|l|}
\hline & Flow Velocity & Minimum Flow Depth \\
\hline Non-trout streams & Up to $1 \mathrm{fps}$ & 4 to 6 in \\
\hline Trout streams & Up to $3 \mathrm{fps}$ & 12 in \\
\hline
\end{tabular}

The next step is to define the path in the culvert available for fish passage for the given conditions. In Figure 2.15 , one end of the path is defined by the culvert wall. The other end of the path, towards the center of the culvert, is defined by the point where the local depth-averaged flow velocity $\mathrm{V}$ is equal to the maximum fish swimming velocity, $V_{F}$, as defined by the appropriate standard. In this illustration example $V_{8}=V_{F}$. Note that another limit to the fish path can be the water depth when the depth in a strip is less than that required for larger species of fish, such as trout or salmon.
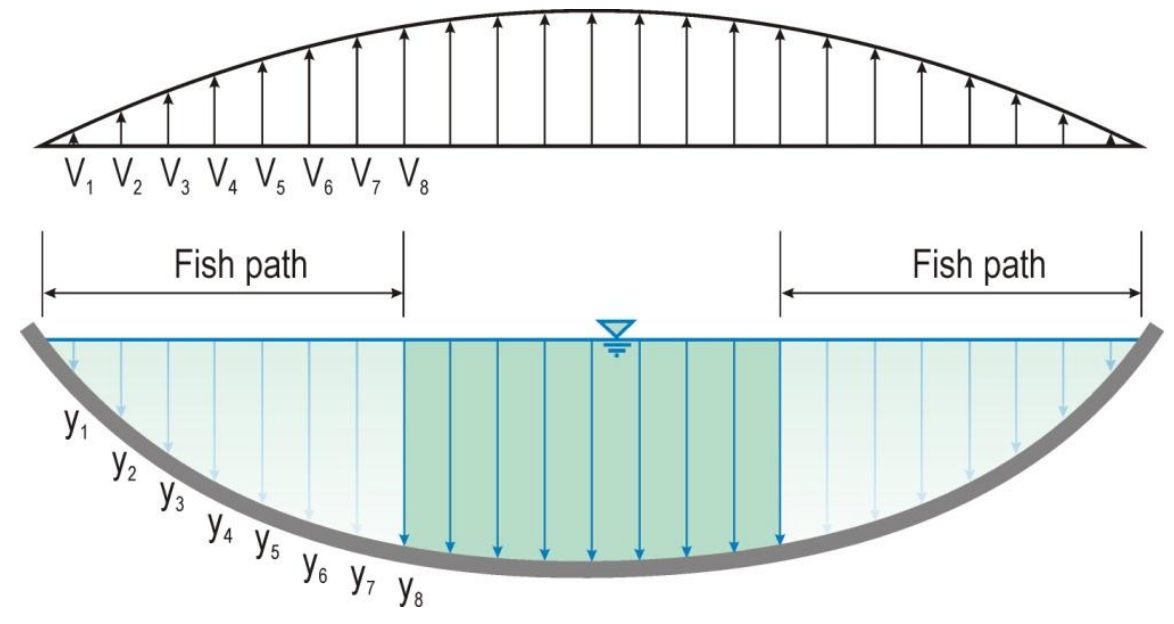

Figure 2.15 Flow path for the selected fish design criteria of velocity and depth

Using the above-mentioned method, the fish path in this project culvert condition is defined. Based on the prototype CFD simulation data, the local depth-averaged velocity curve was created. Take trout as the design objective (see Figure 2.16), the red dot-dashed lines illustrate the maximum velocity of $3 \mathrm{ft} / \mathrm{s}$ $\left(\mathrm{V} / \mathrm{V}_{\mathrm{avg}}=1\right)$, and the purple dashed lines indicate the minimum flow depth of 12 in required by trout. The area between the two curves is suitable for the swimming capacity of trout, which qualifies the flow condition for fish passage. The upper figure (Figure 2.16a) is the condition without gravel bed, while the lower figure (Figure 2.16b) is the condition with 0.15D bed elevation. If the purple dashed lines are between the red dot-dashed lines, the flow condition does not qualify for fish passage. 

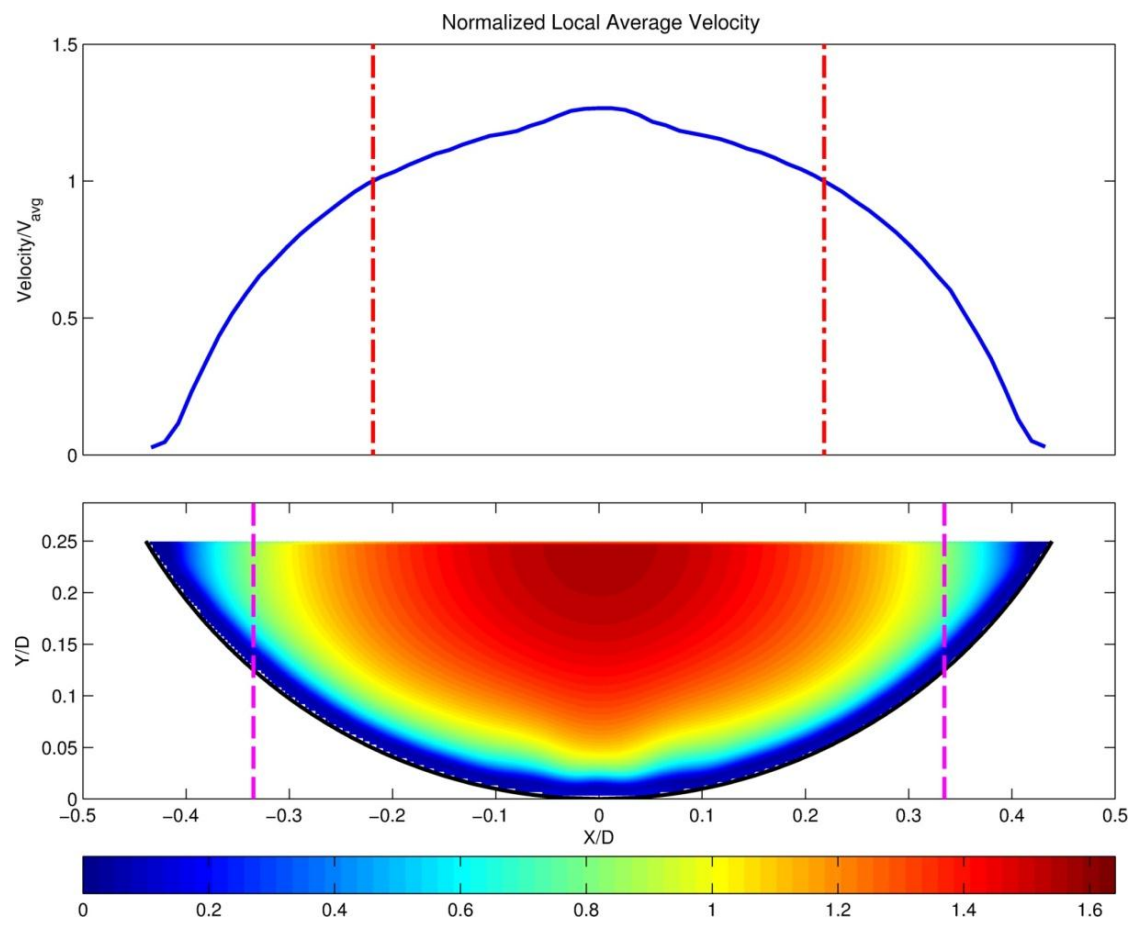

(a) Without gravel bed
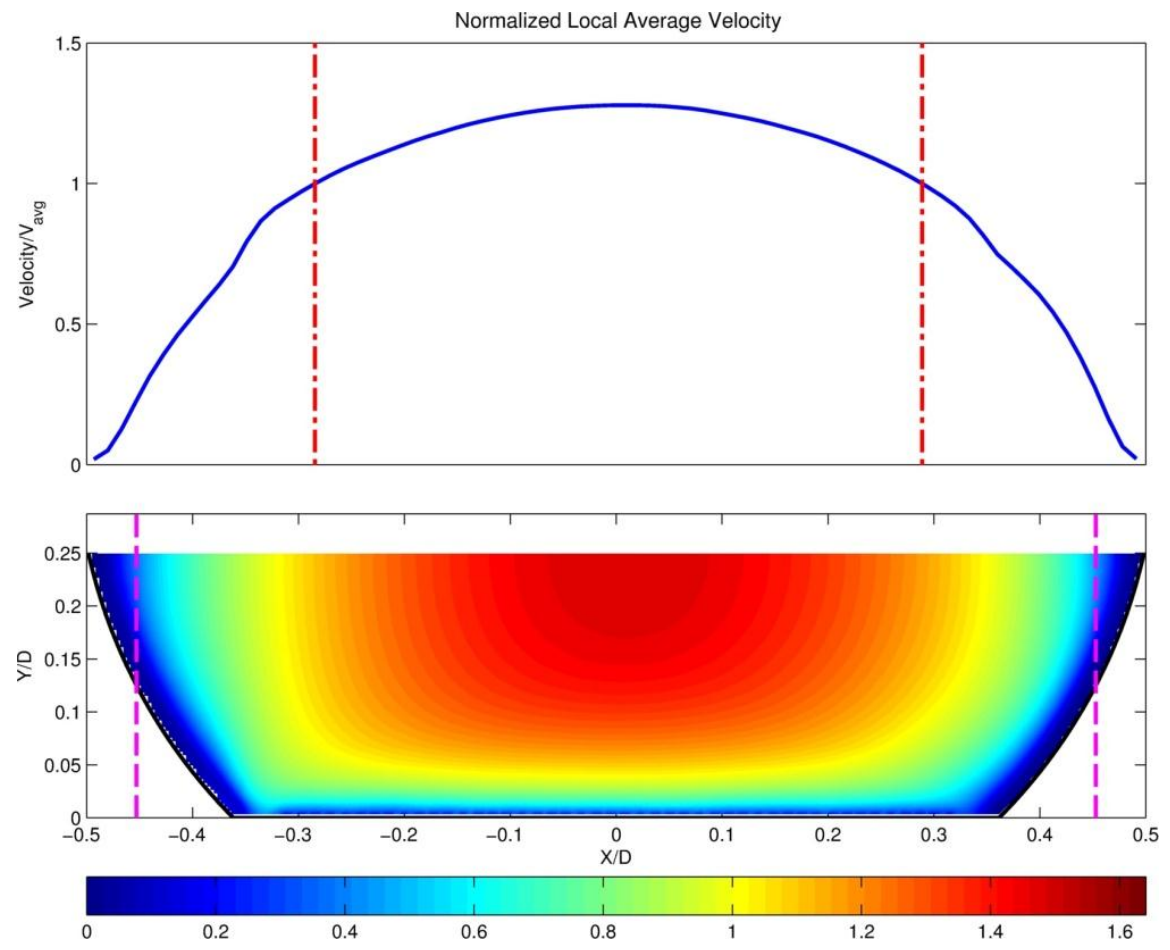

(b) With $0.15 \mathrm{D}$ bed elevation

Figure 2.16 Define fish path based on the combination of dimensionless water depth and flow velocity 


\subsubsection{References}

1. Matt Blank, Joel Cahoon, Tom McMahon, "Advanced studies of fish passage through culverts: 1-D and 3-D hydraulic modeling of velocity, fish expenditure and a new barrier assesment method," Department of Civil Engineering and Ecology, Montana State University, October, 2008 .

2. Marian Muste, Hao-Che Ho, Daniel Mehl,"Insights into the origin \& characteristic of the sedimentation process at multi barrel culverts in lowa", Final Report, IHRB, TR-596, June, 2010.

3. Liaqat A. Khan, Elizabeth W.Roy, and Mizan Rashid, "CFD modelling of Forebay hydrodyamics created by a floating juvenile fish collection facility at the upper bank river dam", Washington, 2008.

4. Angela Gardner, "Fish Passage Through Road Culverts" MS Thesis, North Carolina State University, 2006.

5. Vishnu Vardhan Reddy Pati, "CFD modeling and analysis of flow through culverts", MS Thesis, Northern Illinois University, 2010.

6. Kornel Kerenyi, "Final Draft, Fish Passage in Large Culverts with Low Flow Proposed Tests" unpublished TFHRC experimental and CFD analysis of culvert flow for fish passage work plan, 2011.

7. Young, D. F., Munson, B. R., Okiishi, T. H., and Huebsch, W. W. (2007). "A brief introduction to fluid mechanics: fourth edition." John Wiley and Sons, Inc.

8. Randall, D. (2012). "Dimensional Analysis, Scale Analysis, and Similarity Theories", Revised February 13, 2012.

9. Venkata, S. L. (2011). "Computational fluid dynamics modeling of flow through culverts", Master Thesis, Northern Illinois University.

10. CD-adapco, User Guide STAR-CCM+ Version 6.04.014, 2011.

11. http://www.ptc.com/support/proengineer.htm

12. http://en.wikipedia.org/wiki/Froude_number 


\subsection{New Flume Design for Hydraulics Laboratory at TFHRC}

The large tilting flume at TFHRC will be replaced with a high-speed flume with a live-bed scour testing capability. The flume consists of several sections. The test section is a straight channel with a depression that can be filled with bed material. A long stretch of straight channel is provided before the test section to allow the development of a proper boundary layer for the test section. An inlet that may include a main pipe reception, a diffuser, and a trumpet is connected to the long straight section to feed a wellconditioned flow into the channel. The inlet needs to be designed to provide a sufficiently uniform velocity profile at the entrance of the long straight section. CFD simulation is employed to optimize the geometry to accomplish the desired flow condition under high discharge rate. During this quarter, the study focused on inlet pipe design. The goal of the design was to have water enter through a pipe upstream of the honeycomb as uniformly as possible. CFD studies were conducted to test several possible designs. The geometry of the entry section used in CFD study has slightly evolved from that shown in Figure 2.17 although the fundamental concept remains similar. Water enters from an inlet pipe above the entry section of the flume into an external concentric pipe that is slightly larger than the main inlet pipe and fixed to the flume bed. Concentric slotted cylinders and a porous baffle were tested for the usage as the material for the external pipe to see their performance in disbursing the downward jet of water from the inlet pipe.

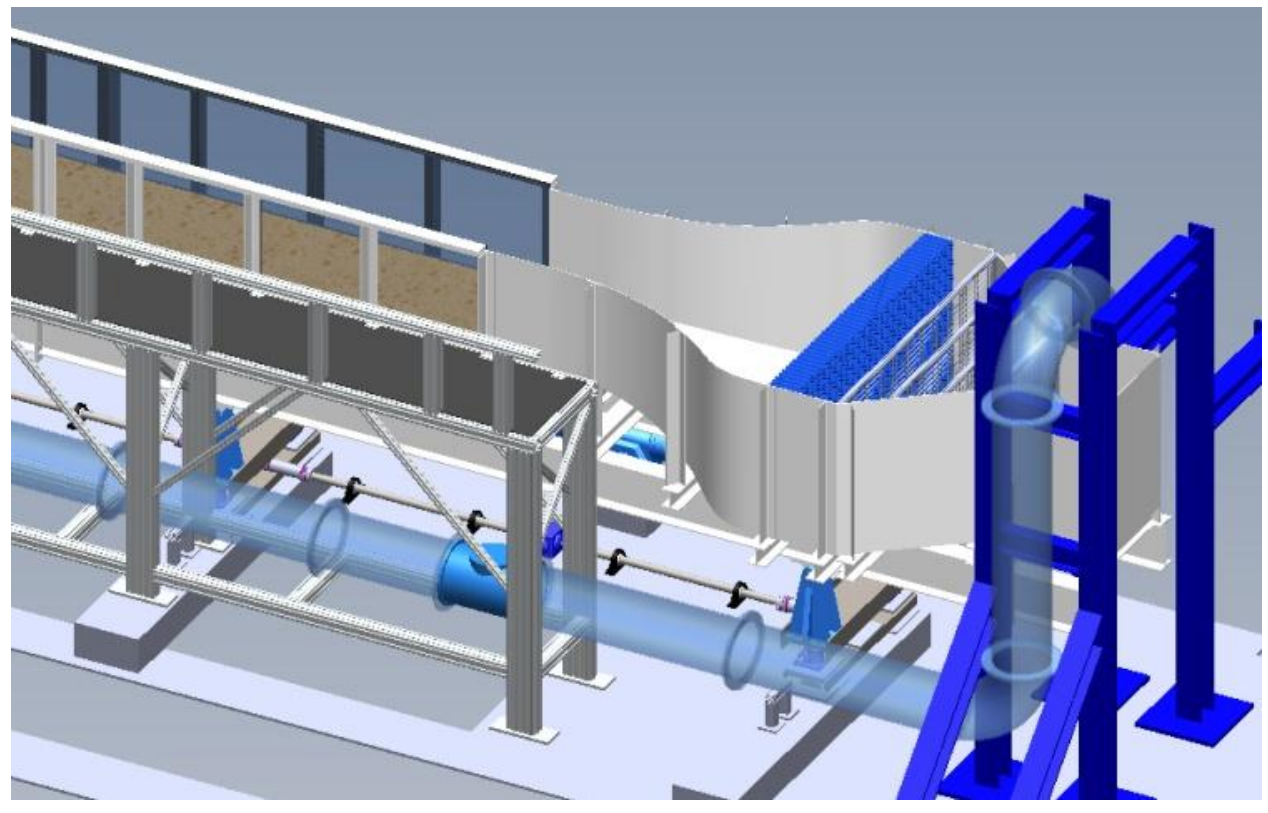

Figure 2.17 A conceptual drawing of the preliminary inlet design

Figure 2.18 shows the velocity vectors in a horizontal cross section in a symmetric half of the flume entry and upstream test section. The concentric cylinder with side slots creates a side jet toward the side walls of the flume inlet section. Two recirculation zones can be seen in the inlet section. The honeycomb forces the flow to go straight toward the downstream. The recirculation zone near the centerline causes more mass and a slightly higher velocity through the honeycomb toward the outer wall of the flume. 


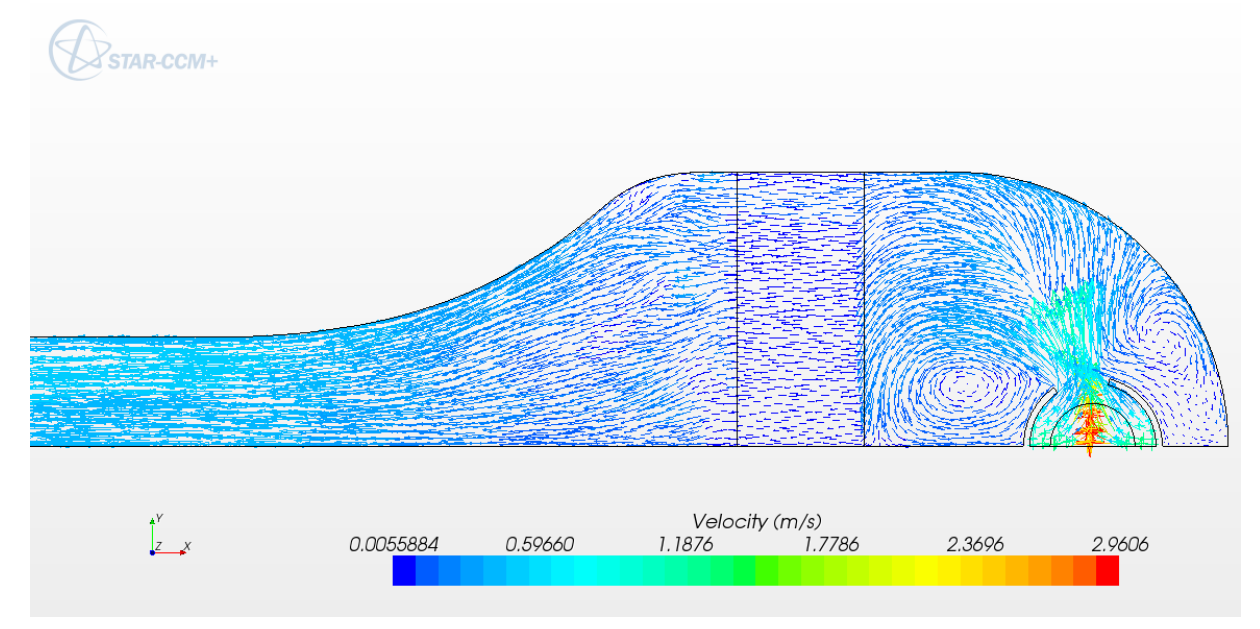

Figure 2.18 Velocity vectors with concentric pipe inlet with large side slot

The recirculation zone near the centerline of the inlet section in Figure 2.18 can be broken up by putting another inlet slot at the centerline in the external inlet pipe. Velocity vectors for this configuration are shown in Figure 2.19. The vortex near the centerline is gone, and flow through the honeycomb and in the test section is more uniform than in the side slot only configuration. However, there are still fairly strong slot jets and vortex structures in the inlet chamber that make the flow through the honeycomb less uniform than it would be if these structures were not present.

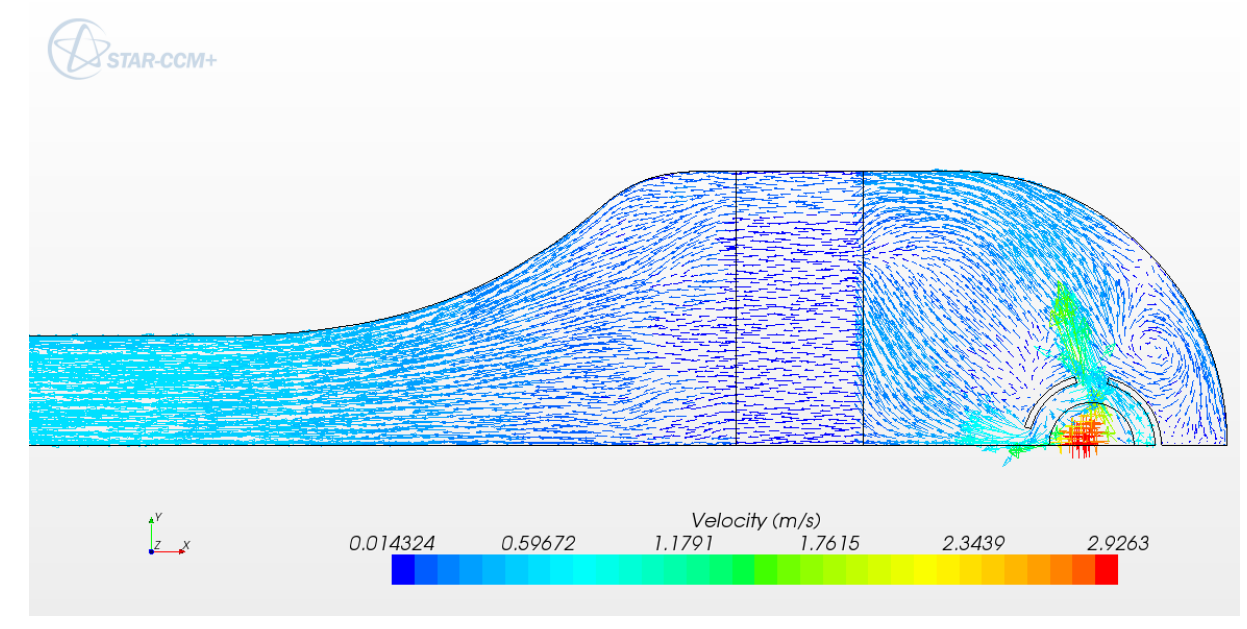

Figure 2.19 Velocity vectors with concentric pipe inlet with front and side slots

Figure 2.20 shows the velocity vector field in the inlet section when the down flow of water from the inlet pipe enters a concentric porous media. In this case the flow is dispersed more evenly into the inlet section, there are no vortex structures, and the flow spreads more evenly into the downstream honeycomb. This configuration yields the most uniform transverse flow in the downstream test section, 
although the difference between this flow and that of Figure 2.19 is small in the test section and not easy to see in these figures.

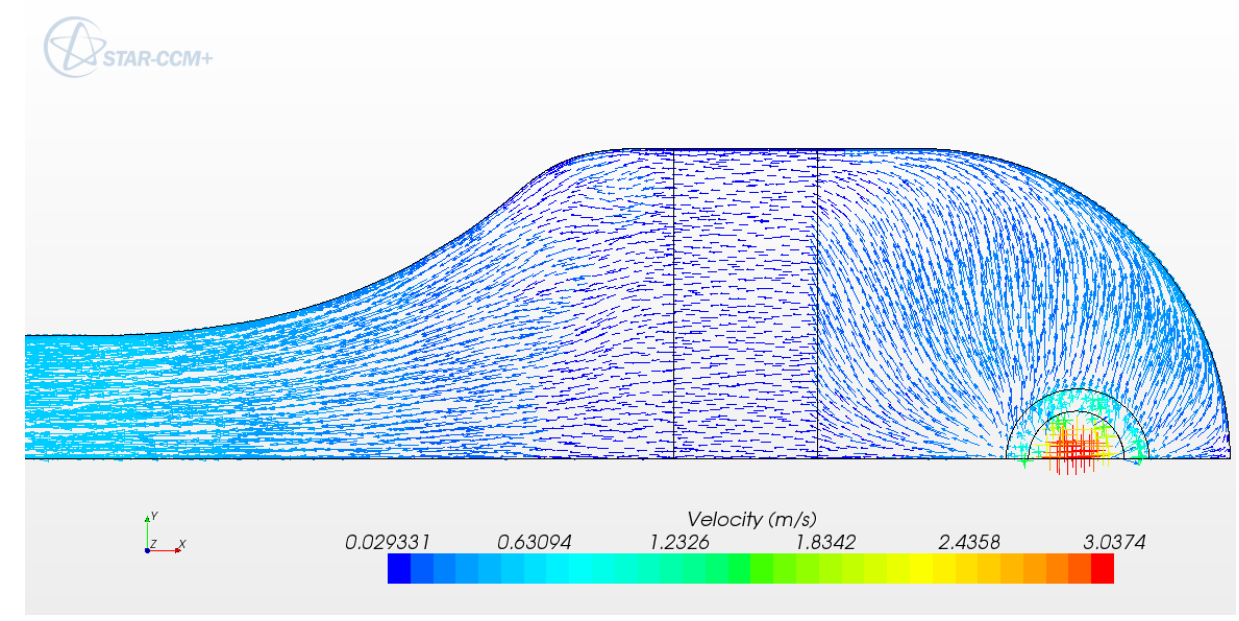

Figure 2.20 Velocity vectors with pipe inlet and concentric porous media 


\subsection{Modeling of Truck Generated Salt Spray under Bridge with Sliding Mesh}

The truck model was significantly improved in the recent quarter. Mud flaps were added to the model geometry. The geometry was cleaned up and a finer level of detail around the wheels was maintained in the mesh by using a smaller cell size at those locations. Those refinements also allowed for better tracking of the parcels colliding with the mud flaps. With the extended boundaries and more detailed mesh the models used for final simulations contained about 5.5 million cells. A final set of simulations was defined to more thoroughly investigate the extent of the tunneling effect and support the main conclusions of the study. Figure 2.21 shows four different geometry conditions underneath the bridge: open, sloped embankment, close wall, and close wall with long approach.
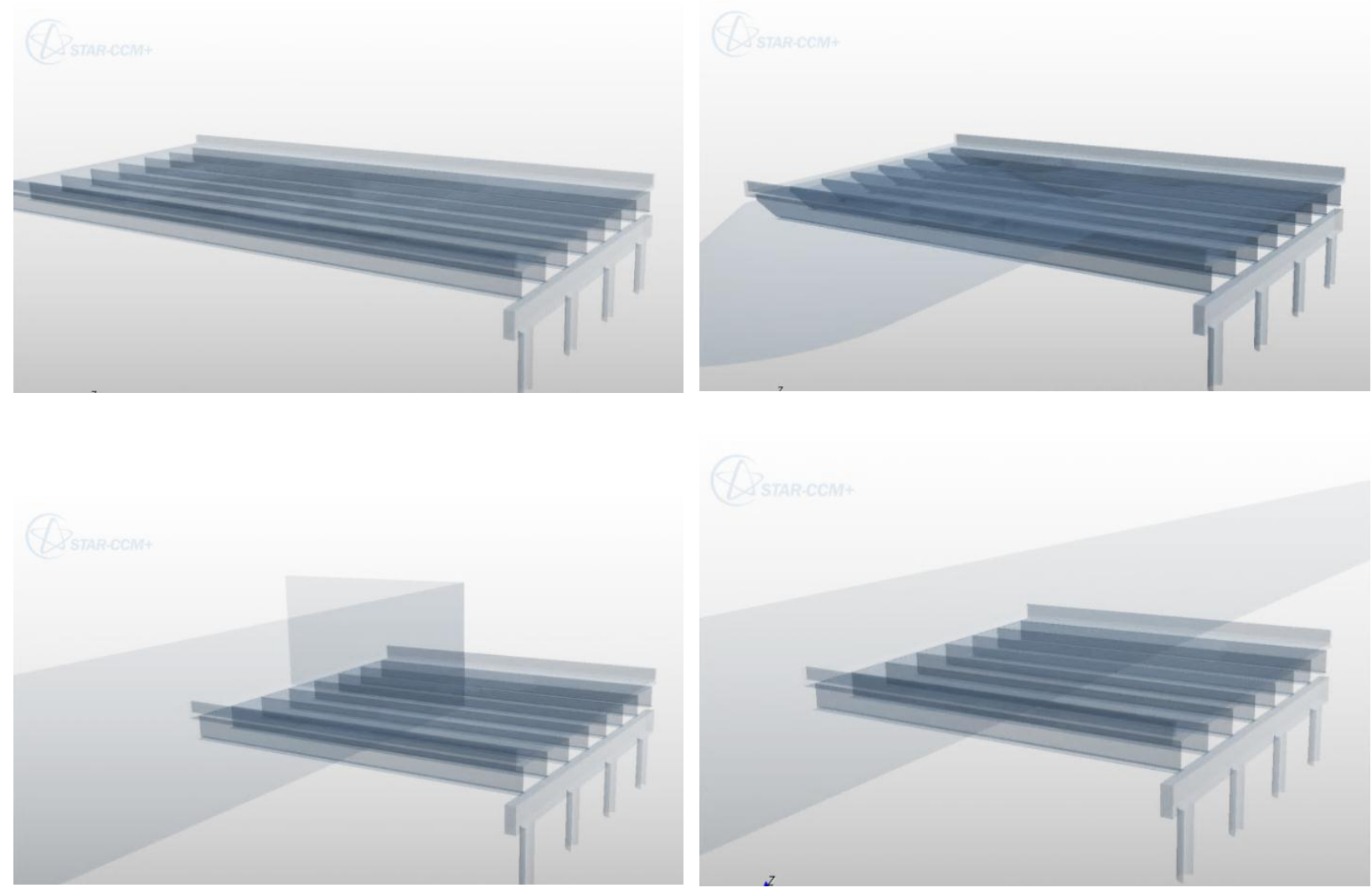

Figure 2.21: Different geometry conditions under the bridge 


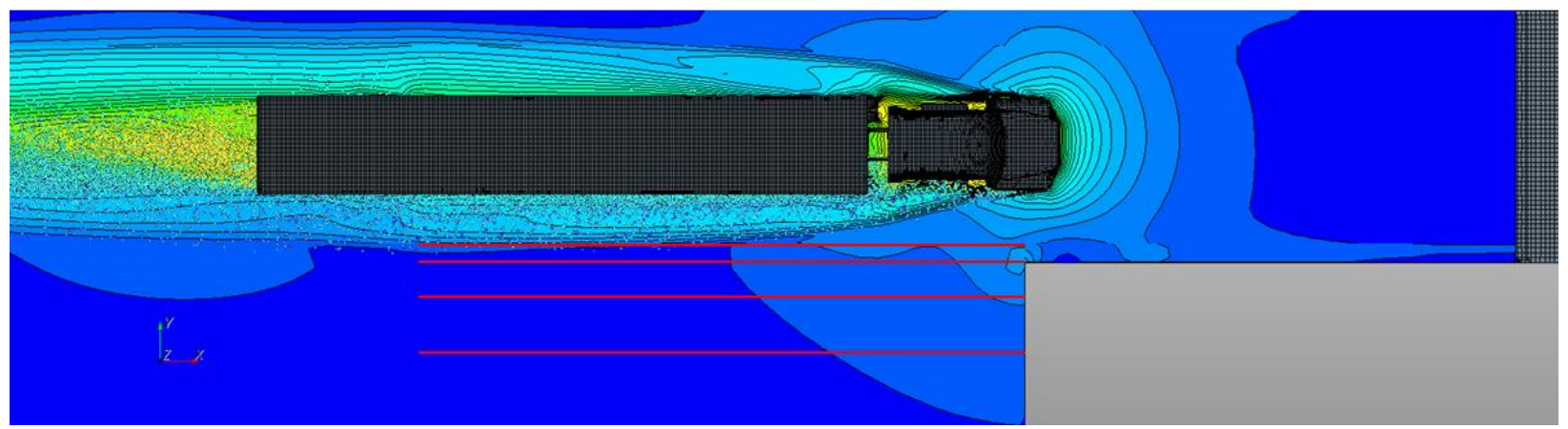

Figure 2.22: Location of the wall for tunneling effect studies

Figure 2.22 shows four different locations of the close wall, indicated by positions of red lines, under the bridge that was used to study in detail the tunneling effect. The positions varied the distance from the truck to the wall.

For each of the basic cases simulations with one and two trucks were studied. The two truck cases were added to include the effect of traffic, specifically large truck traffic, on the amount of salt transported to the bridge beams. For most of the basic cases (without the wind action) three different particle sizes were studied $-0.025 \mathrm{~mm}, 0.05 \mathrm{~mm}$ and $0.10 \mathrm{~mm}$. In addition to the basic cases without the wind, cases with several wind directions were studied. Cases with head and tail wind at the angle of 45 deg were studied. Altogether about 30 simulations were scheduled for the analysis in the recent quarter. Each of them was taking approximately 8 to 14 days to complete depending on the particle size and presence of the wind that slowed down the simulations by increasing the time to compute particle tracks.

Table 2.2: Final set of analyzed cases for salt-spray generation study

\begin{tabular}{|c|c|}
\hline one truck & two trucks \\
\hline open $0.025 \mathrm{~mm}$ & open $0.025 \mathrm{~mm}$ \\
\hline open $0.05 \mathrm{~mm}$ & open $0.05 \mathrm{~mm}$ \\
\hline open $0.1 \mathrm{~mm}$ & open $0.1 \mathrm{~mm}$ \\
\hline wall (4 ft gap) $0.025 \mathrm{~mm}$ & wall $(5.5 \mathrm{ft}$ gap) $0.025 \mathrm{~mm}$ \\
\hline wall (4 ft gap) $0.05 \mathrm{~mm}$ & wall (5.5 ft gap) $0.05 \mathrm{~mm}$ \\
\hline wall (4 ft gap) $0.10 \mathrm{~mm}$ & wall $(5.5 \mathrm{ft}$ gap) $0.10 \mathrm{~mm}$ \\
\hline wall (4 ft gap) $0.05 \mathrm{~mm}$ tail wind, left side & wall $(5.5 \mathrm{ft}$ gap) $0.05 \mathrm{~mm}$ tail wind, left side \\
\hline wall (5.5 ft gap) $0.05 \mathrm{~mm}$ & slope $0.025 \mathrm{~mm}$ \\
\hline wall (9 ft gap) $0.05 \mathrm{~mm}$ & slope $0.05 \mathrm{~mm}$ \\
\hline wall (14 ft gap) $0.05 \mathrm{~mm}$ & slope $0.10 \mathrm{~mm}$ \\
\hline long wall (5.5 ft gap) $0.05 \mathrm{~mm}$ & slope $0.05 \mathrm{~mm}$ tail wind, left side \\
\hline long wall (14 ft gap) $0.05 \mathrm{~mm}$ & \\
\hline
\end{tabular}




\begin{tabular}{|c|c|}
\hline slope $0.025 \mathrm{~mm}$ & \\
\hline slope $0.05 \mathrm{~mm}$ & \\
\hline slope $0.10 \mathrm{~mm}$ & \\
\hline slope $0.05 \mathrm{~mm}$ tail wind, left side & \\
\hline slope $0.05 \mathrm{~mm}$ tail wind, right side & \\
\hline slope $0.05 \mathrm{~mm}$ head wind, left side & \\
\hline slope $0.05 \mathrm{~mm}$ head wind, right side & \\
\hline
\end{tabular}

The results from the simulations will be presented in the next quarterly report. The main results will consist of: (1) histograms presenting particle distribution based on their Z-position (elevation from road surface) underneath the bridge for different stages of the simulations, and (2) cumulative plots summing up the number of particles at the bridge beam levels. The cumulative counts of droplets at the beam level reduce the data for each case to a single number. This data reduction allows for a simple comparison of different cases using bar graphs. Figure 2.23 presents an example of such a plot for the basic cases for one and two trucks. The results are showing clearly the large influence of traffic on the number of parcels at the bridge beam level. The full spectrum of results and their analysis will be sent to TFHRC in a separate final report of the project and in the next quarterly report.

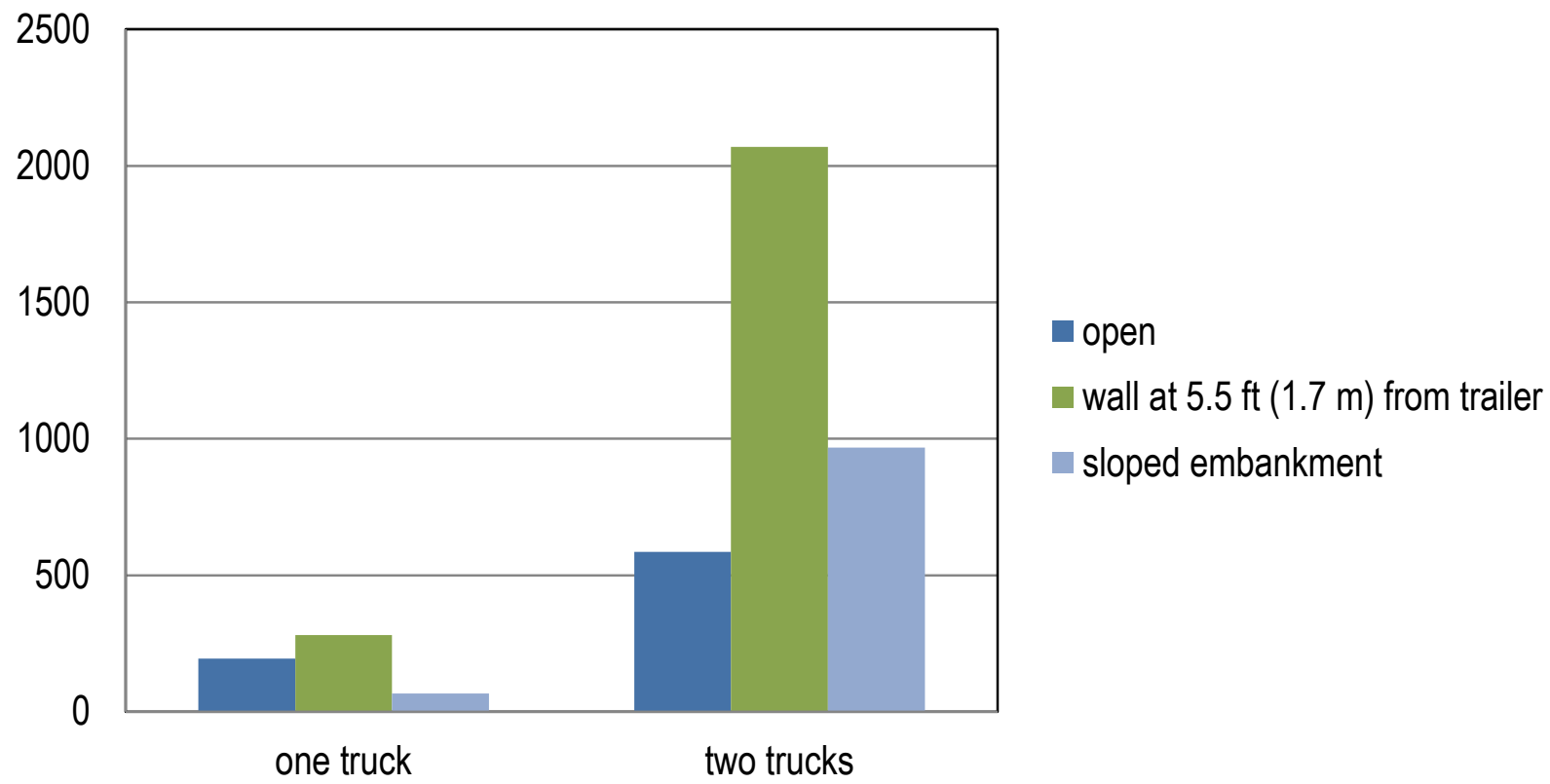

Figure 2.23: Cumulative plot presenting number of parcels at the bridge beam level in basic cases 


\subsection{Modeling of In-situ Scour Testing Device Design Alternatives}

The initially tested design of an in-situ scour testing device consisted of a propeller as its main part creating shear stress on the soil surface. However, the spinning propeller did not create a uniform shear stress distribution. Additionally under its axis of rotation the stress was zero - a dead zone (see Figure 2.24 for shear stress distribution).

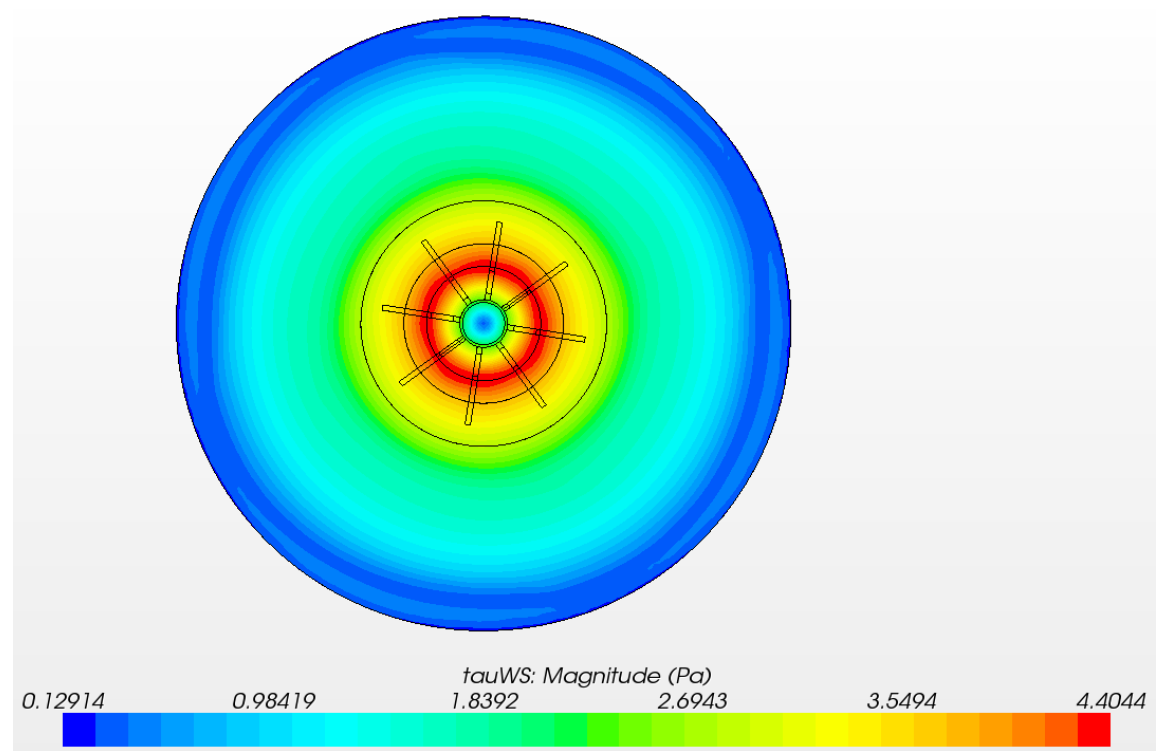

Figure 2.24: Real shear stress distribution on the bottom

To prevent this from happening several modifications to the design were considered:

- Off centered propeller(s)

- Special design of curved blades

- Combination of the propeller with a jet

Two of ideas for the off centered propellers are shown in Figure 2.25 - a case with one propeller and a case with two propellers with different sizes. In this quarter the case with one off centered propeller was tested using CFD modeling. In the model two motions were implemented: (1) rotation of the propeller around its own axis and (2) rotation of the propeller around the center of the domain. Of main interest in the simulation was the distribution of the shear stresses on the bed surface. 

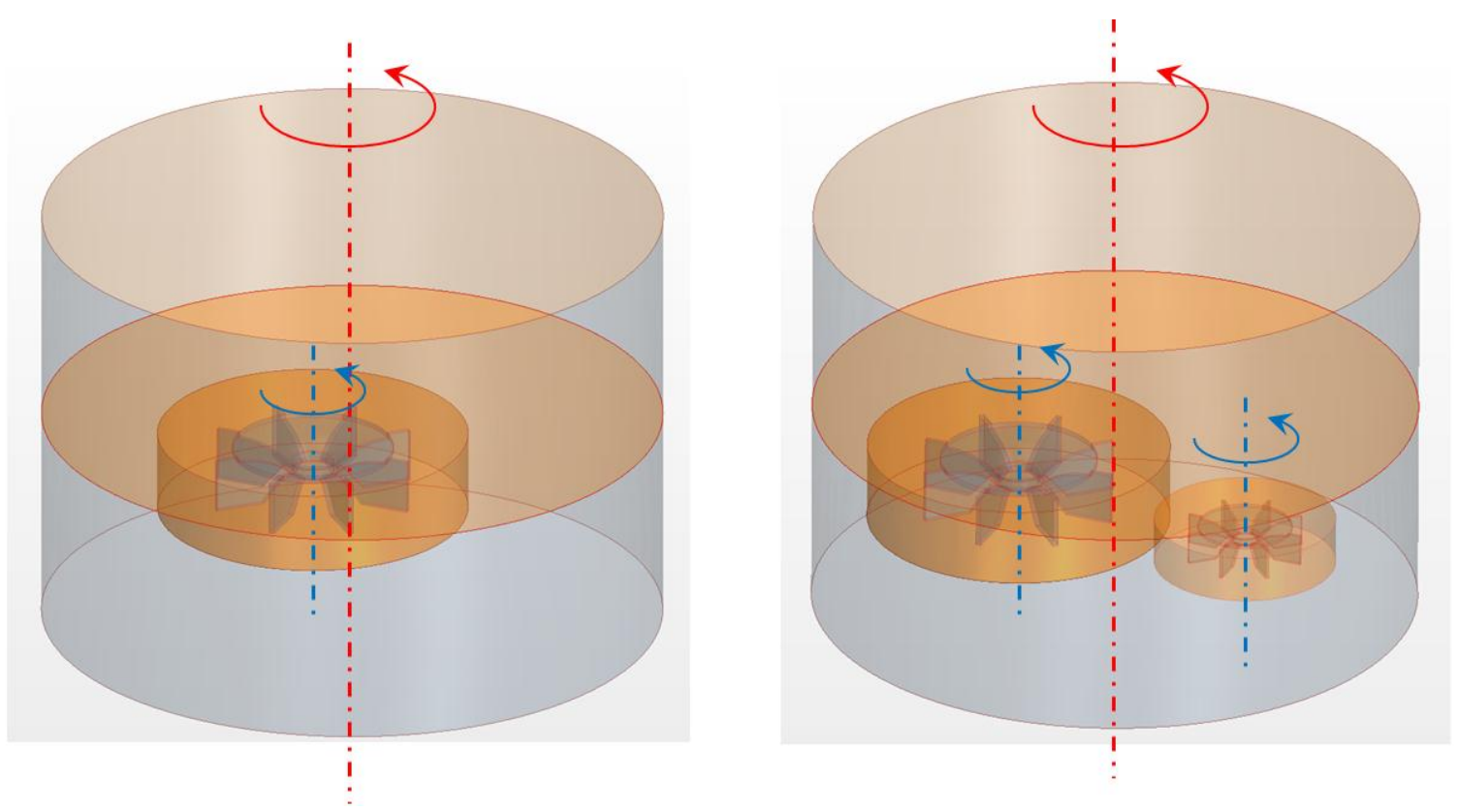

Figure 2.25: Off centered propellers

The off center propeller also creates a non-uniform shear distribution but the secondary motion of it around the main axis of the model causes the maximum and minimum shear stress zones to travel with the propeller. That way the area on the bed that undergoes a period of high shear stress can be made large and without permanent dead zones. Characterization of the varying shear in order to determine erosion rates as a function of shear stress may be challenging with this design concept.
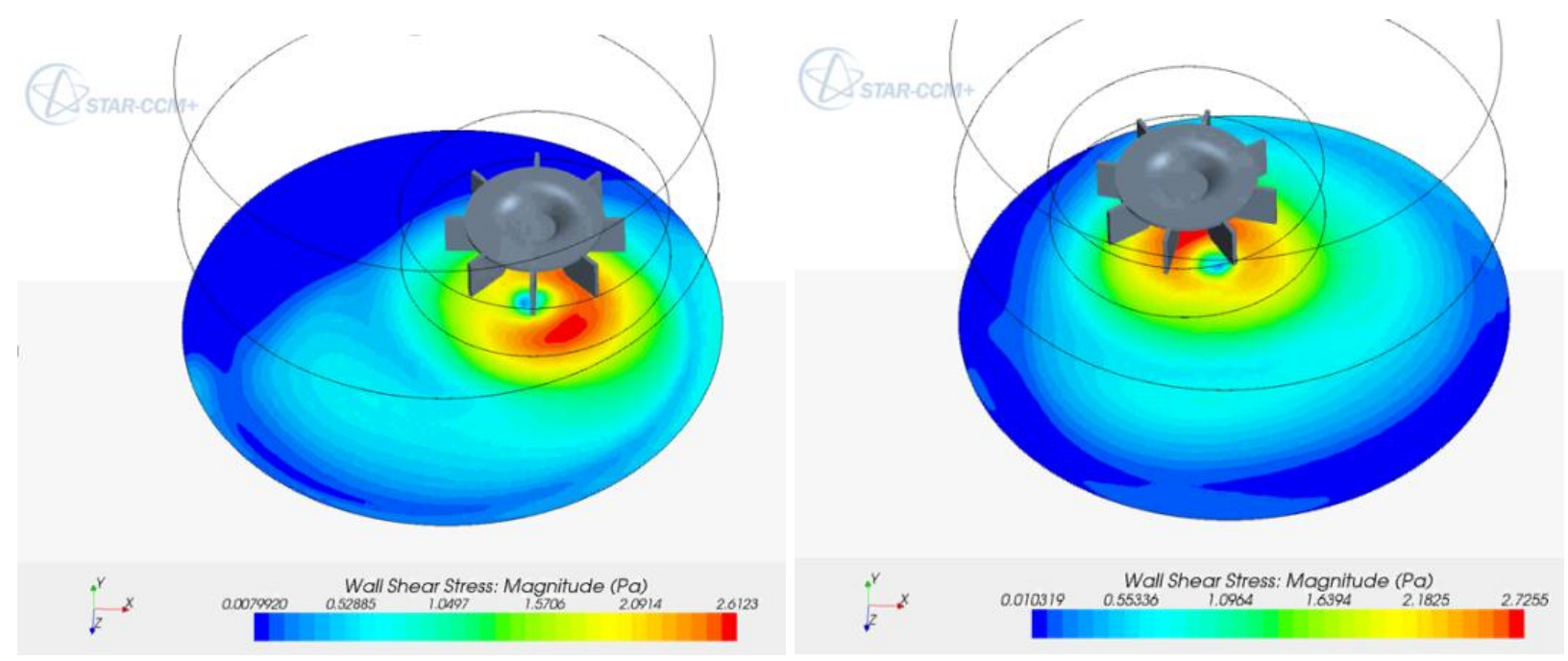

Figure 2.26: Shear stress distribution under the propeller at two different time instances

To investigate the shear stress history on the bed 12 probe points were defined on the bottom of the model. They run from the center of the model outward along a straight line as shown in Figure 2.27. Shear stress history was stored at these points in the simulation of six full rotations of the propeller about the main axis of the model. 


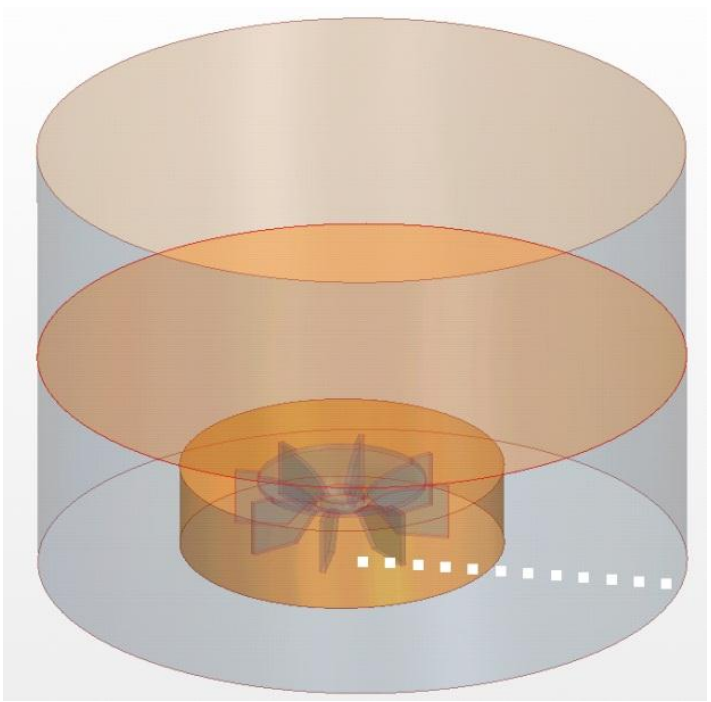

Figure 2.27: Location of point probes for shear stress histories

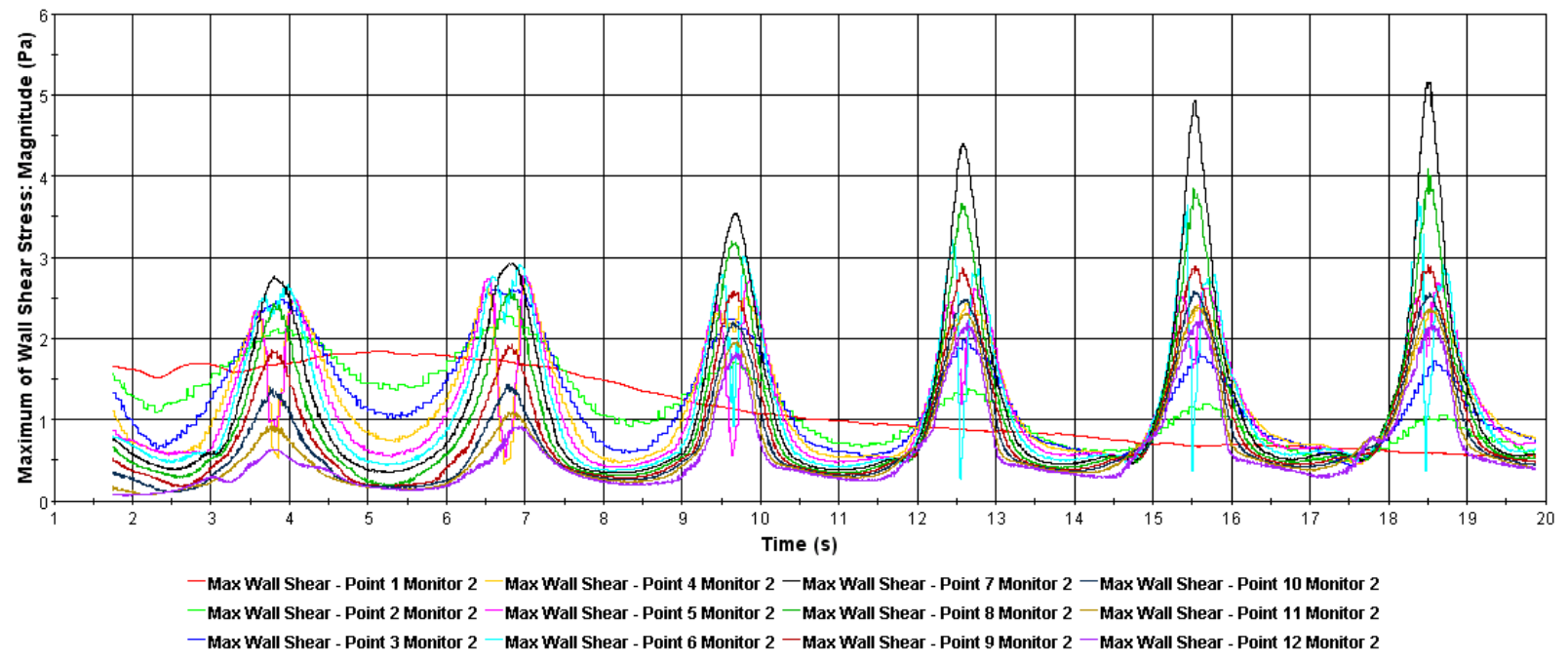

Figure 2.28: Shear stress at radial monitor points

Figure 2.28 shows the shear stress at the radial monitor points for six revolutions of the propeller around the chamber. The results indicate that there is an initial, probably non-physical transient where secondary flow structures are being established in the chamber in addition to the primary traveling vortex generated by the propeller that is increasing the shear stress at the monitoring points over time. Note that the peaks at most of the monitoring points are increasing with each circular traverse of the propeller around the chamber. Eventually the pattern of one cycle should repeat. While the pattern shown here may not be entirely physical, it does indicate that a device of this design may have a significant startup time during which the scour cannot be easily correlated with bed shear. In addition bed shear is varying significantly with time and the maximums vary from point to point in the radial direction, and this variation may also make it difficult to establish a relation between erosion rate and shear stress for different soil types. 


\subsection{Training and Technology Transfer}

Technology transfer of high performance computational analysis techniques is an important part of Argonne's work to support and advance engineering and research programs at TFHRC. The technology transfer is accomplished by publishing techniques developed and the work done in reports and papers,

presentations at conferences, and training courses in CFD offered by TRACC. Plans for presentation of the truck salt spray analysis at the Bridge Task Force Meeting in Chicago in August are being made. Arrangements to take the TRACC booth to 2012 National Hydraulics Engineering Conference (NHEC) in Nashville, TN in August are also in place. A technical presentation of TRACC's CFD hydraulic modeling and analysis of problems of interest to the TFHRC is also scheduled for the NHEC conference. 


\section{Computational Multiphysics Mechanics}

\subsection{Multiphysics Coupling of STAR-CCM+ and LS-DYNA for Bridge and Cable Analysis under Wind Loading}

In the current quarter work on multiphysics modeling of bridge cable vibrations has been started. Vibrations of the cables can be categorized as a Fluid Structure Interaction problem where air (fluid) induces vibrations of the cable (structure) and the vibrating cable disturbs the flow of the air. FSI problems are still regarded as a cutting edge research area and there is no single established approach to treat these problems. Also there is currently no easy choice of software capable of solving flow around bodies that undergo large deformations without significant development and setup effort by the user. However, to some degree multiphysics problems can be handled by the following commercial software:

- COMSOL

- ANSYS

- ABAQUS

- $\quad$ LS-DYNA

- STAR-CCM+

The problem of cable vibration involves not only addressing FSI itself but also large elastic deformations of cable. Although fluid codes like STAR-CCM+ can handle some FSI problems, this one is out of its current scope. LS-DYNA and ABAQUS can handle large deformations of structures but their fluid flow capabilities are limited. The recently released LS-DYNA CFD solver is not well tested yet and it also doesn't have a large community of users. The most reliable option at this time appears to be the coupling of two solvers - a widely used and well tested CFD solver to solve the flow field and a similar major CSM software to solve for displacements.

The problem of coupling the two different types of software involves transfer of the results between two codes and (what is most difficult) mapping the results from one computational grid to another. The structural code requires usually a different mesh than the fluid code and as a result interpolation between the surfaces is required. CD-adapco has developed two way coupling algorithms for STAR$\mathrm{CCM}+$ and ABAQUS (Also they are currently working on two-way coupling with the NASTRAN structural solver). That seems to be the purest approach to coupling as it reduces user interference in the data exchange process. However, TRACC currently doesn't have an ABAQUS license (due to low usage by external users and associated high license cost).

A more generic way of coupling through user scripting and automatic results mapping within STAR$\mathrm{CCM}+$ is also available. This approach only requires that the external structural solver accepts NASTRAN result files and is able to produce NASTRAN based displacement output files.

Since TRACC has a large pool of LS-DYNA licenses and LS-PREPOST can translate results from calculations to NASTRAN format it was decided that coupling between STAR-CCM+ and LS-DYNA will be investigated 
to solve a FSI problem of wind induced cable vibration. This coupling was never tested by CD-adapco but according to the information provided by the user support representatives, it is possible.

In the recent weeks a simple example of a straight vertical cable subject to a $60 \mathrm{mph}$ wind load was studied as a test case to establish steps required in the coupling process. Geometry files that include the pressure loading on surfaces produced by STAR-CCM+ are translated using Python scripts to LS-DYNA input format. The coupling procedure passes the pressure loading from STAR-CCM+ to LS-DYNA and displacements from the deformed model computed in LS-DYNA are passed back to STAR-CCM+ for the next iteration. The deformed object displacements computed in LS-DYNA are used to displace surfaces in STAR-CCM+ and morph the mesh to maintain computational cell quality.

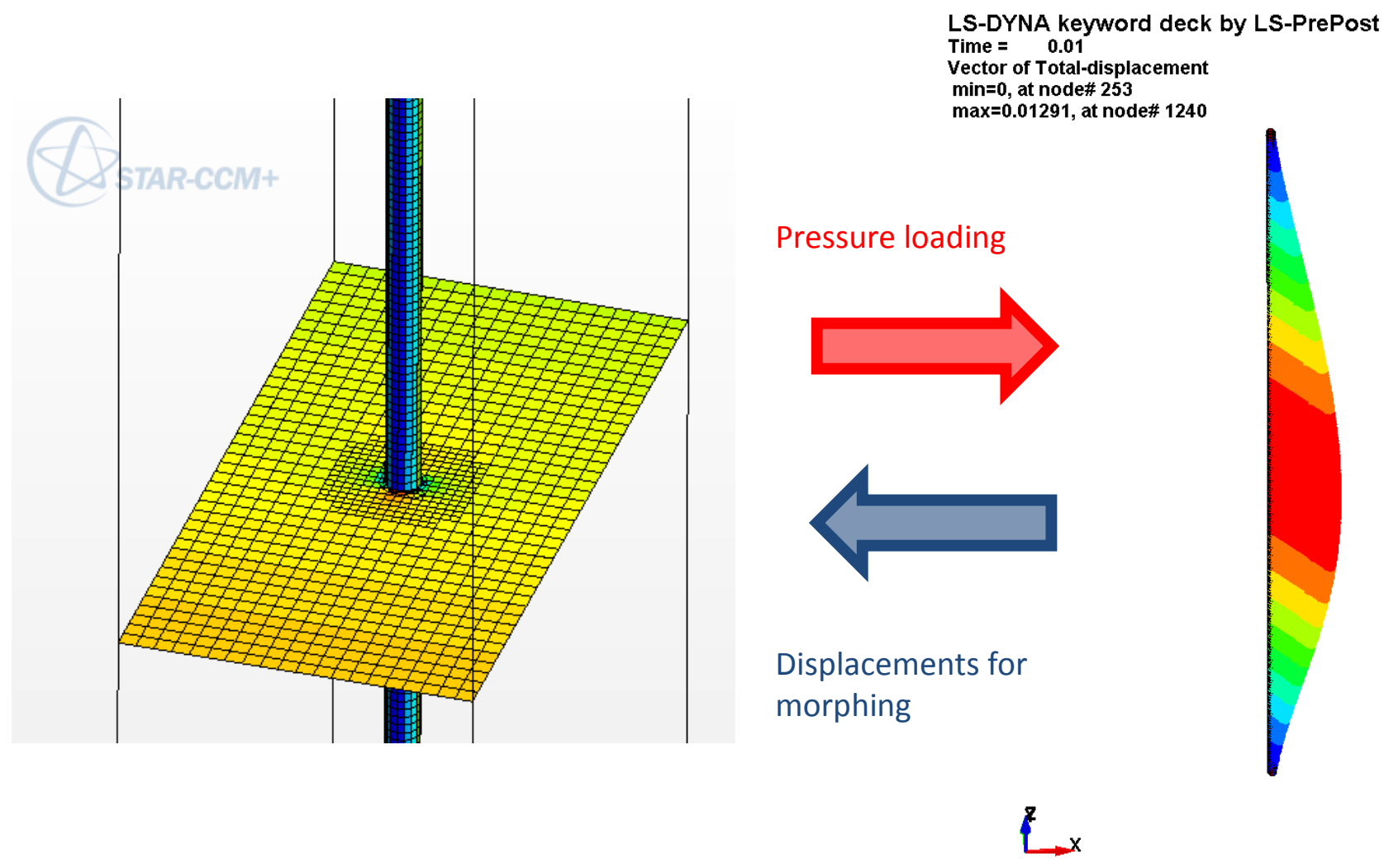

Figure 3.1 Scheme of coupling between LS-DYNA and STAR-CCM+

The whole coupling process in detail was established as follows:

1. Import geometry, morph the model to a new geometry and run the STAR-CCM+ simulation for a time step to obtain a new pressure distribution acting on cable

Input filename: cable_(i).sim

2. Run a Java macro in STAR-CCM+ to extract pressures on the cable surface and export them in Nastran format

Input filename: extract_pressure.java 
Output filename: import_pressure_(i).nas

3. Run Python script PressureForDyna.py to convert import_pressure_(i).nas to Is-dyna element load format.

Input filename: import_pressure_(i).nas

Output filename: LOAD_ELEMENT_(i).k

4. Run LS-DYNA simulation to obtain a set of surface displacements of the cables Input filename: cable_vibration.k

5. Run Python script to create cmfile for LS-DYNA PREPOST (LSPP) software module.

Output filename: extract_displacements_(i).cmfile

6. Run LSPPv2.4 in batch mode to obtain nodal displacements in LS-DYNA format

Input filename: d3plot

Output filename: extract_displacements_(i).dat

7. Run Python script DisplacemnetsForNastran.py to convert nodal displacements to NASTRAN format

Input filename: extract_displacements_(i).dat

Output filename: import_displacements_(i).nas

8. Run Java macro in STAR-CCM+ to import cable displacements for morphing Input filename: import_displacements.java

9. Go to step 1 until finished

The entire procedure is executed by an external Python wrapper script. The script is run on the TRACC Phoenix Linux cluster by using the following command:

./CouplingWorkflow.py input.sim <starting iteration><max number of iterations> 〈STAR-CCM+ timestep of calculations>

The procedure to create the initial set of files for running a coupled case, i.e. building the base models is also quite involving, and thus it is described here as well. The following steps need to be performed before the coupling script is executed.

1. Create geometry in LSPP - an un-deformed geometry of the cable or other deformable objects needs to be created. For this case it was performed within LSPP.

2. Create the mesh for LS-DYNA.

3. Run LS-DYNA without any load on the cable just for one step.

4. From the LS-DYNA result file (d3plot) export the NASTRAN mesh.

5. Import the mesh through the CAE model import tool to STAR-CCM+. The name of the file has to be cable.nas.

6. Import the same as a surface mesh - create new Boundary called Cable.

7. Import CAE solution - 0 displacement vector to set up the mapping. 
8. Initialize solution.

9. Define coupling on import in the Imported Models node of the STAR-CCM+ object tree.

10. Set up morphing of the Cable boundary as linear displacement with field function set to mapped imported displacement.

In the first example the time step of calculations for an unsteady RANS implicit STAR-CCM+ simulation was set to $0.01 \mathrm{~s}$. The LS-DYNA explicit solver was selected to account for inertia effects. The LS-DYNA time step was set to $0.00001 \mathrm{~s}$. The overall time of simulation was set to 1 second. The calculations were performed on one node of the TRACC cluster. For now that is a limitation of the scripts, but the limitation can be removed in the future. For such conditions the computation took around 8 hours. In Figure 3.2 deformation of the cable computed by LS-DYNA and flow around it computed by STAR-CCM+ are shown.

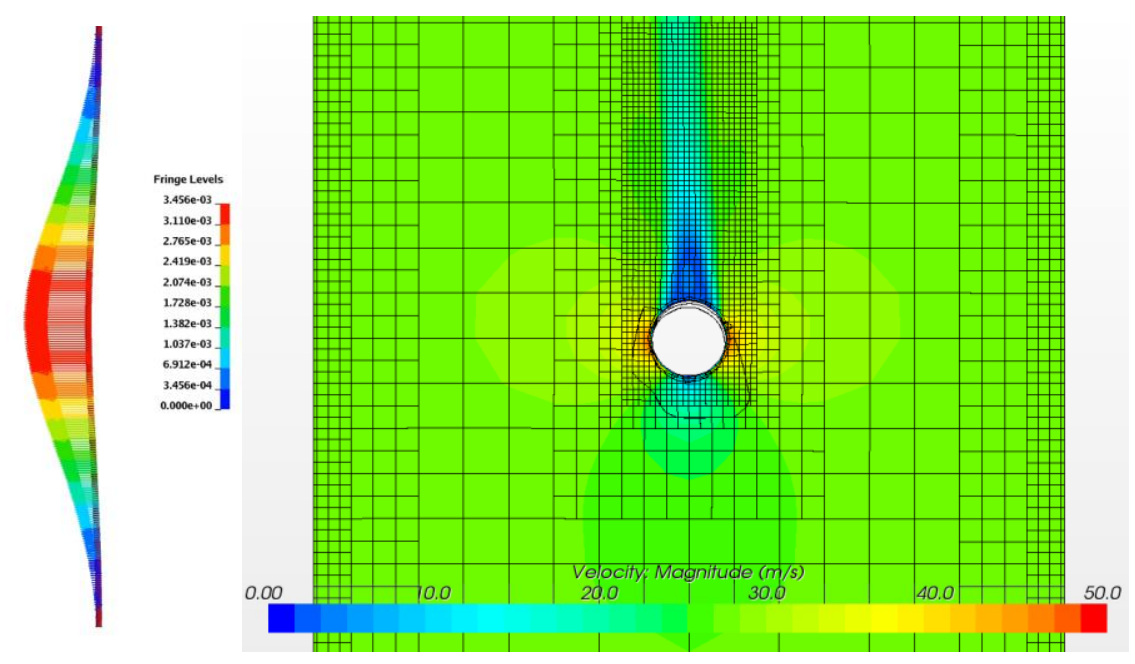

Figure 3.2 Deformation of the cable (left) and flow around it (right) after $0.4 \mathrm{sec}$.

Several studies on including global damping in the LS-DYNA simulations were also conducted. The damping is important for proper initialization of the system. Without it a sudden load is applied to the cable, and that may lead to exaggerated vibrations of the cable. Figure 3.3 shows oscillations of the cable with different damping values. Problems with continuing simulations where damping was used were encountered. However, proper use of restart parameters in the LS-DYNA input file prevented failure of the simulations. 


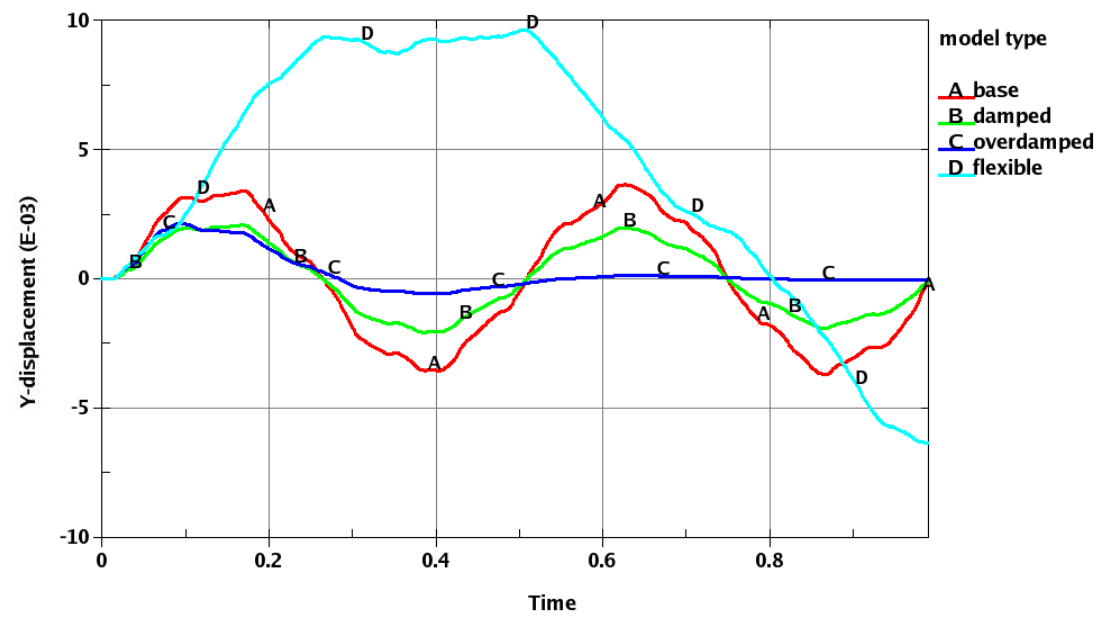

Figure 3.3 Oscillations of the cable in simulations with different damping parameters

The next test case analyzed was an inclined cable subject to gravitational force and the same $60 \mathrm{mph}$ wind. A simple case was considered with no pre-tensioning and soft material properties - just to exaggerate the effect of sag. As it has turned out, the LS-DYNA structural code can handle such cases without problems. However, there are limitations to the extent of morphing of the mesh in STAR-CCM+. When the total displacement of a surface in a morphed mesh becomes large, remeshing needs to be performed to maintain adequate mesh cell quality. In the case where large deformations are expected a smaller time step is required. Figure 3.4 shows a deformed cable under the gravitational force and lateral wind loading. Soft properties of the cable caused large deformation and significant amount of stretching of the mesh in the morphing process.

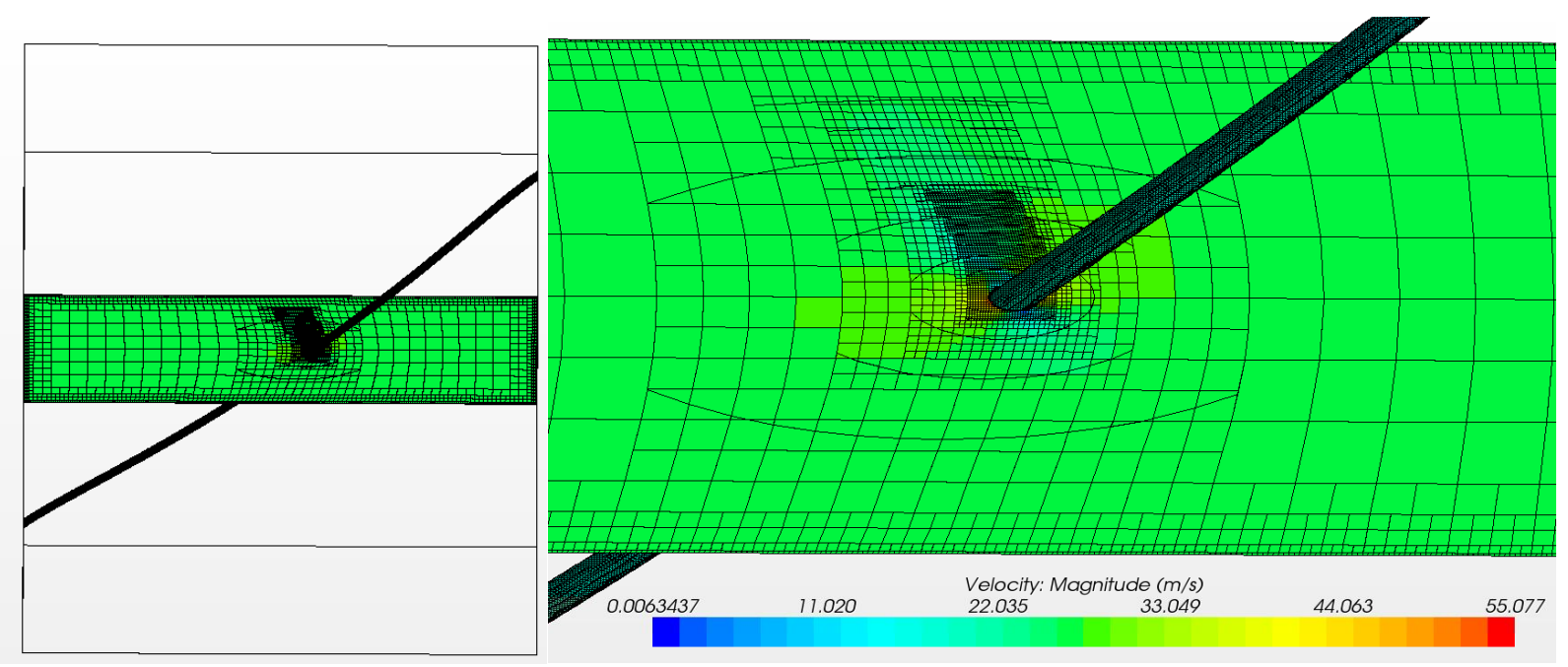

Figure 3.4 Deformed cable and morphed mesh around it. 


\section{Argonne}

\section{Energy Systems Division}

Argonne National Laboratory

9700 South Cass Avenue, Bldg. 362

Argonne, IL 60439-4815

www.anl.gov

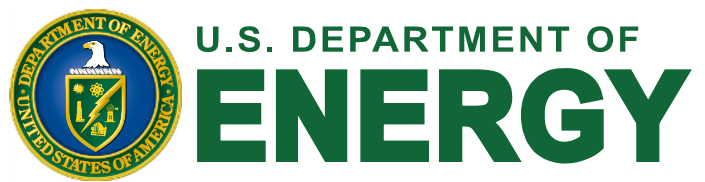

Argonne National Laboratory is a U.S. Department of Energy laboratory managed by UChicago Argonne, LLC 